ISSN: 0213-2079 - ISSN electrónico: 2386-3889

DOI: https://doi.org/10.14201/shhmo2019411407433

\title{
LOS PROYECTOS DEL CUARTEL DE INFANTERÍA PARA LA CIUDAD DE ZAMORA EN EL PRIMER TERCIO DEL SIGLO XVIII
}

\section{The projects of the Infantry Barracks for the city of Zamora in the first third of the XVIII century}

\section{Daniel LÓPEZ BRAGADO}

Universidad de Valladolid

Correo-e.: daniel.lopez.bragado@uva.es

Víctor-Antonio LAFUENTE SÁNCHEZ

Universidad de Valladolid

Correo-e.: victorantonio.lafuente@uva.es

RESUMEN: Zamora comenzó el siglo XVIII con una gran actividad castrense fruto de la guerra con Portugal. La ciudad se convirtió en el punto de retaguardia del frente de guerra por la que pasaron gran número de soldados. Para albergar a la tropa se construyó un cuartel en los primeros años del siglo, pero su capacidad pronto se vio desbordada debido al aumento de efectivos, por lo que el Consistorio y el gobernador, solicitaron la edificación de un nuevo cuartel para albergar a las unidades de infantería.

Se pretende aquí estudiar el proceso de construcción de los distintos edificios militares así como las circunstancias que impidieron la materialización de varios proyectos de acuartelamiento en el barrio ribereño de La Horta.

Palabras clave: Zamora; restitución gráfica; cuartel militar; patrimonio desaparecido.

ABSTRACT: Zamora began the eighteenth century with a great military activity fruit of the war with Portugal. The city became the rearguard point of the war front, through which a large number of soldiers passed. To house the troops a barracks was built in the first years of the century, but its capacity soon was overflowed due to the increase of troops, so the Consistory and the governor, requested the construction of a new barracks to house the units of infantry. 
DANIEL LÓPEZ BRAGADO Y VÍCTOR-ANTONIO LAFUENTE SÁNCHEZ

LOS PROYECTOS DEL CUARTEL DE INFANTERÍA PARA LA CIUDAD DE ZAMORA

EN EL PRIMER TERCIO DEL SIGLO XVIII

The aim is to study the construction process of the different military buildings as well as the circumstances that prevented the materialization of several cantonment projects in the riverside neighborhood of La Horta.

Keywords: Zamora; graphic restitution; military headquarters; missing heritage.

\section{INTRODUCCIÓN}

El siglo XVIII comenzó para los zamoranos con un periodo de sequía, lo que agravaba las penurias económicas y el hambre. A esta lamentable situación, se le unió la declaración de guerra del nuevo monarca Felipe V, que en 1704 promulgó en Plasencia «por la fe, por la corona y por el honor de la patria (...) declaro enemigos al rey de Portugal, al Archiduque Carlos de Austria y a todos sus aliados».

El cambio de monarca y el estado de guerra propiciaron que se sustituyeran los cargos establecidos por el anterior soberano, entre ellos el nombramiento de Gonzalo Zegri como nuevo gobernador de Zamora. Éste realizó un censo de personas y armas, además de dar la orden para la construcción de un cuartel. La plaza de Zamora se consideraba estratégica, por lo que pronto se movilizaron oficiales irlandeses y tropas francesas enviadas por Luis XIV, hasta un total de dos batallones de infantería y tres escuadrones de caballería ${ }^{1}$.

Como la tensión iba en aumento, en 1705 se ordenó el alistamiento de uno de cada cinco vecinos a veinte leguas de la frontera y, posteriormente, todos los varones mayores de catorce años. Un año después, el numeroso ejército enemigo había tomado Ciudad Rodrigo, Salamanca y Ledesma, por lo que la ciudad fue defendida ante un eventual ataque armando a todos los vecinos y solicitando doscientos hombres de localidades cercanas ${ }^{2}$. Finalmente, el ataque no se produjo, aunque se dieron constantes escaramuzas portuguesas en gran parte de las zonas fronterizas de Aliste, Sayago y Alba, hasta la localidad de Carbajales ${ }^{3}$. Las tropas españolas tomaron la ciudad fronteriza de Miranda do Douro ese mismo año. Los portugueses respondieron recuperando Miranda, asolando la tierra de Alba y conquistando

1. GONZALO ZEGRI DE SALAZAR fue un sargento general de batalla a las órdenes de Felipe V, haciéndose cargo de la gobernación civil y militar de Zamora desde 1704 hasta 1707, momento en el que ascendió a superintendente general de las Rentas Reales. Lo sucedió en el cargo de gobernador de Zamora el marqués de Villafuerte. MUÑOZ MIÑAMBRES, José: Porque Zamora es asi: siglo XVIII. Zamora, Imprenta Jambrina, 2000, p. 34.

2. Alcañices envió cien soldados a caballo. CARRACEDO PRIMO, José E.: Historia militar de Zamora desde el siglo XVIII. Zamora, Instituto de Estudios Zamoranos Florián de Ocampo, Diputación de Zamora, 2014, p. 20.

3. CARRACEDO PRIMO, José E. op.cit., p. 19.

Ediciones Universidad de Salamanca / @@ Stud. his., H. ${ }^{a}$ mod., 41, n. 1 (2019), pp. 407-433 
DANIEL LÓPEZ BRAGADO Y VÍCTOR-ANTONIO LAFUENTE SÁNCHEZ LOS PROYECTOS DEL CUARTEL DE INFANTERÍA PARA LA CIUDAD DE ZAMORA EN EL PRIMER TERCIO DEL SIGLO XVIII

Carbajales, que sería recuperada por España en junio del año siguiente ${ }^{4}$. Esta situación se calmó tras la finalización de la guerra en $1713^{5}$, aunque el trasiego de tropas por la ciudad continuó a lo largo de todo el siglo XVIII.

Como indica el título del artículo, a lo largo de estas líneas se tratará de aclarar el proceso de construcción de cuarteles durante del primer tercio de siglo. Al inicio de dicha centuria Zamora contaba únicamente con el castillo medieval como sede de la milicia, incapaz de albergar el movimiento constante de tropas que se produjo sobre todo en los momentos posteriores a la finalización de la guerra con el país vecino. Dicha circunstancia obligó a construir un cuartel de Caballería junto al río Duero. $\mathrm{Al}$ poco de su entrada en funcionamiento, las autoridades locales, desbordadas con la cantidad de soldados movilizados a la ciudad, solicitaron la construcción de un cuartel, pero en este caso de Infantería. Los problemas surgieron desde dicho momento, ya que por distintos problemas que a continuación se recogen, existieron tres proyectos de este nuevo cuartel de infantería, todos ellos situados en el barrio ribereño de la Horta, aunque ninguno llegó a materializarse.

Finalmente, el ansiado cuartel se construiría, pero lejos de este punto, en lo que se denominaba la zona del «Palomar Grande», en un descampado al noreste dentro del recinto amurallado (Fig. 1). Cabe mencionar que la ubicación de este cuartel estuvo precedida de otra en las Cortinas de San Miguel - mencionada al final de este artículo- (Fig. 1), finalmente desechada y que provocó que se dilatara aún más el proceso, no siendo hasta 1765 el momento de la puesta en marcha de este ansiado cuartel de Infantería 6 .

Con el fin de ayudar a entender el cuartel de Caballería y el Pajar del Rey - desaparecidos - y los tres proyectos del cuartel de Infantería - no construidos -, se ha creído relevante llevar a cabo una serie de restituciones gráficas que muestren las imágenes de estos edificios. Esta metodología se enmarca dentro de los estudios llevados a cabo en investigaciones como la del profesor Eduardo Carazo sobre el patrimonio desaparecido del centro histórico de Valladolid ${ }^{7}$, así como el estudio de épocas precedentes de la plaza de la Catedral de Oviedo, autoría de la profesora Marta Alonso ${ }^{8}$.

4. MUÑOZ MIÑAMBRES, José: op.cit., p. 41.

5. Aunque Puebla de Sanabria permaneció ocupada por los portugueses hasta el día de nochebuena de 1715. CARRACEDO PRIMO, José E. op.cit., p. 22.

6. LÓPEZ BRAGADO, Daniel; LAFUENTE SÁNCHEZ, Víctor-Antonio: «La construcción de edificios militares en el tercio central del siglo XVIII en la ciudad de Zamora». En Anuario 2017. Zamora: Diputación de Zamora, Instituto de Estudios Zamoranos Florián de Ocampo, 2018, pp. 279-318.

7. CARAZO LEFORT, Eduardo: Valladolid: forma urbis: restitución infográfica del patrimonio urbano perdido. Valladolid: Ayuntamiento de Valladolid, 2009.

8. ALONSO RODRÍGUEZ, Marta: «El ensanche de la plaza de la Catedral de Oviedo. Estudio y restitución gráfica», en Revista EGA. Valencia: Editorial de la Universitat Politècnica de València, 2014, pp. 242-251.

Ediciones Universidad de Salamanca / అ@@ Stud. his., H. ${ }^{a}$ mod., 41, n. 1 (2019), pp. 407-433 
DANIEL LÓPEZ BRAGADO Y VÍCTOR-ANTONIO LAFUENTE SÁNCHEZ LOS PROYECTOS DEL CUARTEL DE INFANTERÍA PARA LA CIUDAD DE ZAMORA EN EL PRIMER TERCIO DEL SIGLO XVIII

\section{ZAMORA NECESITABA UN CUARTEL}

Cuando en 1703 se trasladó a Zamora un regimiento de los Dragones de la Reina, el Ayuntamiento declaró no tener medios para acuartelar tal cantidad de soldados, aunque «verán la forma de que no les falte forraje ni lo demás» ${ }^{9}$. Las tropas se alojaron en casas particulares de la ciudad y alrededores, y los oficiales residieron en modo de alquiler en inmuebles de mayor calidad, propiedad de los regidores de la ciudad.

La continuidad de las hostilidades con Portugal dejaba a Zamora como núcleo de retaguardia del frente. La previsión de más tropas y la continuidad de su estancia en la ciudad provocaron que el Consistorio y el gobernador Gonzalo Zegri comenzaran las diligencias el 23 de febrero de 1704 para solicitar al Consejo Real la construcción de un cuartel en Zamora ${ }^{10}$. En estos primeros momentos, la Corona era incapaz de realizar el proyecto por medios propios, ya que, ante la precariedad de medios humanos a causa de la Guerra de Sucesión, la red de ingenieros militares aún no estaba consolidada. Era común que realizara el proyecto algún maestro de obras local, como así ocurriría en este caso ${ }^{11}$. Diego Carrascal y su yerno José de Barcia ${ }^{12}$ trazaron las plantas y las «condiciones» para la edificación del cuartel de Caballería $^{13}$. Este edificio se diseñó con capacidad para un regimiento de tres escuadrones de caballería pudiendo alojar además un batallón de infantes ${ }^{14}$.

9. Archivo Histórico Provincial de Zamora (en adelante AHPZa), Municipal Zamora, Actas, 1703, f. 163v.; ALMARAZ VÁZQUEZ, Mercedes y BLANCO SÁNCHEZ, José Ángel: «Consideraciones sobre el arquitecto José de Barcia». En Stvdia Zamorensia. Zamora, Colegio Universitario de Zamora, Centro Asociado de la UNED, 2008, Segunda Etapa, vol. VIII, p. 151.

10. Archivo General de Simancas, Sección de Guerra (en adelante AGS, SGU), leg. 3285. Febrero de 1713. FERNÁNDEZ DURO, Cesáreo: Memorias Históricas de Zamora, su provincia y obispado. Madrid, 1888, t. III, p. 82. Parte de los documentos que aparecen en este artículo están referenciados por SÁNCHEZ RIVERA, María Luisa: Fuentes documentales zamoranas en el Archivo de Simancas. Zamora, Diputación de Zamora, Instituto de Estudios Zamoranos Florián de Ocampo, 1990; y VEGA VIERA, Víctor-Javier: «Planos y dibujos de la ciudad de Zamora en el Archivo General de Simancas». En Actas de Fuentes y métodos de la historia local. Zamora, Instituto de Estudios Zamoranos Florián de Ocampo, 1991, pp. 205-232.

11. CAPEL, Horacio et alii: De Palas a Minerva: la formación cientifica y la estructura institucional de los ingenieros militares en el siglo XVIII. Barcelona, Serbal, 1988, p. 293.

12. JOSÉ DE BARCIA (1677-1757) fue un arquitecto zamorano que aprendió el oficio de su suegro Diego Carrascal, ya Barcia provenía de una familia de campaneros. Su buen hacer le convirtió en una personalidad que asesoraba técnicamente sobre obras municipales o militares. Nunca ocupó el cargo de arquitecto municipal, aunque si el de maestro mayor del obispado, llegando a ser uno de los regidores de la ciudad. ALMARAZ VÁZQUEZ, Mercedes y BLANCO SÁNCHEZ, José Ángel: op.cit., pp. 149-179.

13. El plano realizado por Carrascal y Barcia no se conserva, aunque existen planos de años posteriores que indican su estado inicial. AGS, Mapas Planos y Dibujos (en adelante MPD), XI-114 y XI-116 y Servicio Geográfico del Ejército, sección de documentación, nº 344.

14. CAPEL, Horacio et alii: op.cit., p. 41.

Ediciones Universidad de Salamanca / 요 Stud. his., H. ${ }^{a}$ mod., 41, n. 1 (2019), pp. 407-433 
DANIEL LÓPEZ BRAGADO Y VÍCTOR-ANTONIO LAFUENTE SÁNCHEZ LOS PROYECTOS DEL CUARTEL DE INFANTERÍA PARA LA CIUDAD DE ZAMORA EN EL PRIMER TERCIO DEL SIGLO XVIII
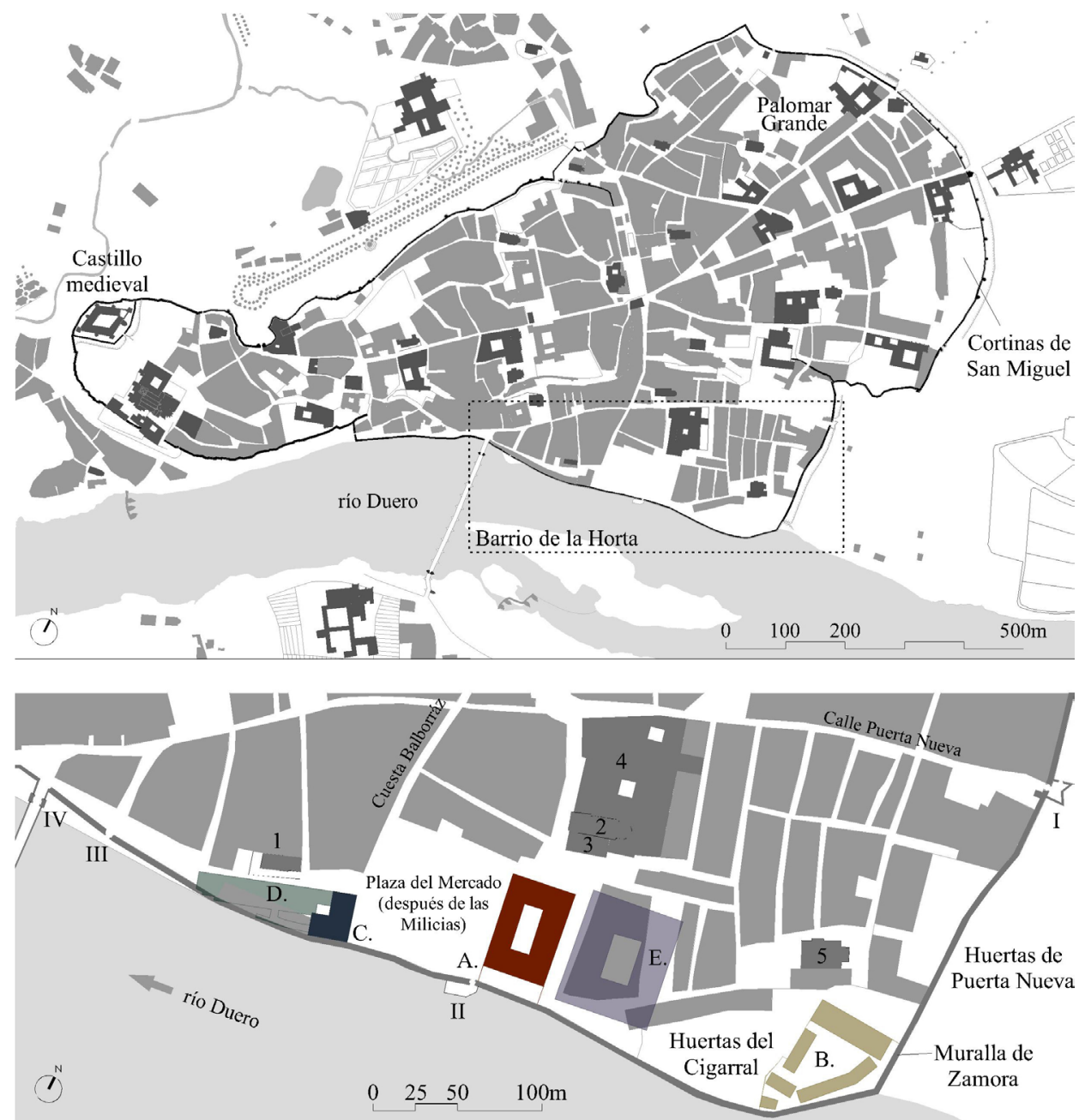

\begin{tabular}{lll}
\hline 1. Iglesia de San Julián & I. Puerta Nueva & A. Cuartel de Caballería (1703) \\
\hline 2. Iglesia de Sta. $\mathrm{M}^{\mathrm{a}}$ de la Horta & II. Puerta de Tajamar & B. Propuesta a base de pabellones (1721) \\
\hline 3. Atrio cubierto de la iglesia & III. Puerta de las Ollas & C. Pajar del Rey (1735) \\
\hline 4. Convento de S. Juan de Jerusalén & IV. Puerta del Puente & D. Propuesta sobre el Pajar del Rey (1737) \\
\hline 5. Iglesia de Santo Tomé & & E. Propuesta en paralelo (1738) \\
\hline
\end{tabular}

Fig. 1. Plano de Zamora en el siglo XVIII en el que se resaltan las iglesias y los conventos. En la parte inferior la situación de las distintas propuestas cuarteleras del barrio de la Horta sobre el estado de la ciudad en el siglo XVIII (elaboración propia tomando como plano base AHPZa, $M P y, D, 711)$.

Ediciones Universidad de Salamanca / 
El edificio era de grandes dimensiones y necesitaba de una plaza de armas frente a él para formaciones militares. Se optó por ocupar parte de la plaza del Mercado de San Julián, en el barrio de la Horta. Se situó en su lado oriental, ocupando un tercio de la misma. La fachada principal del edificio se orientó al oeste, quedando alineada con la puerta de Tajamar de la muralla medieval de Zamora (Fig. 1).

El barrio de la Horta estaba débilmente densificado, este síntoma se sentía aún más en el extremo sur del barrio, junto a la muralla, donde se situaban las huertas del Cigarral. La plaza del Mercado, además de tener ese uso comercial, representaba el escenario de las fiestas de la ciudad junto con la plaza Mayor, siendo la cuesta de Balborraz la vía de conexión de ambos espacios urbanos.
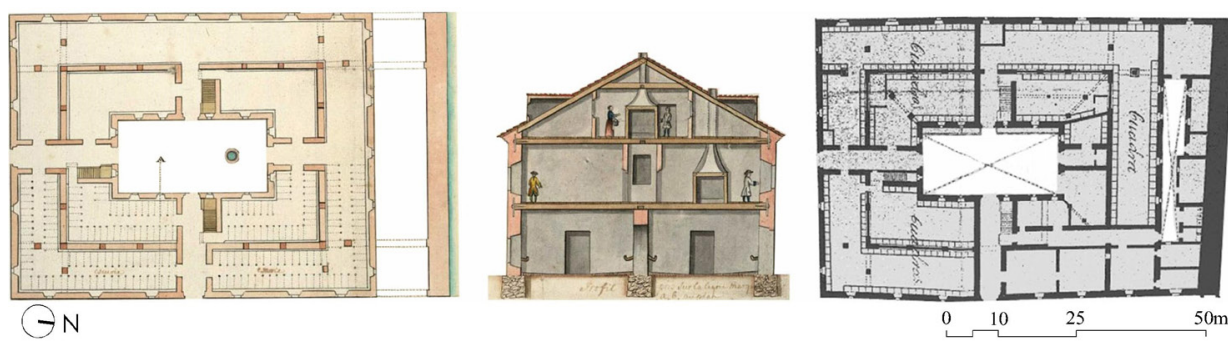

Fig. 2 Planta y sección del cuartel de Caballería en 1721 y en 1911 (AGS, MPD, 11-114. La planta de la derecha pertenece a AHPZa, Hacienda, 40 (provisional). Incluida en Mercedes ALMARÁZ VÁZQUEZ y José Ángel BLANCO SÁNCHEZ: op.cit., p. 153).

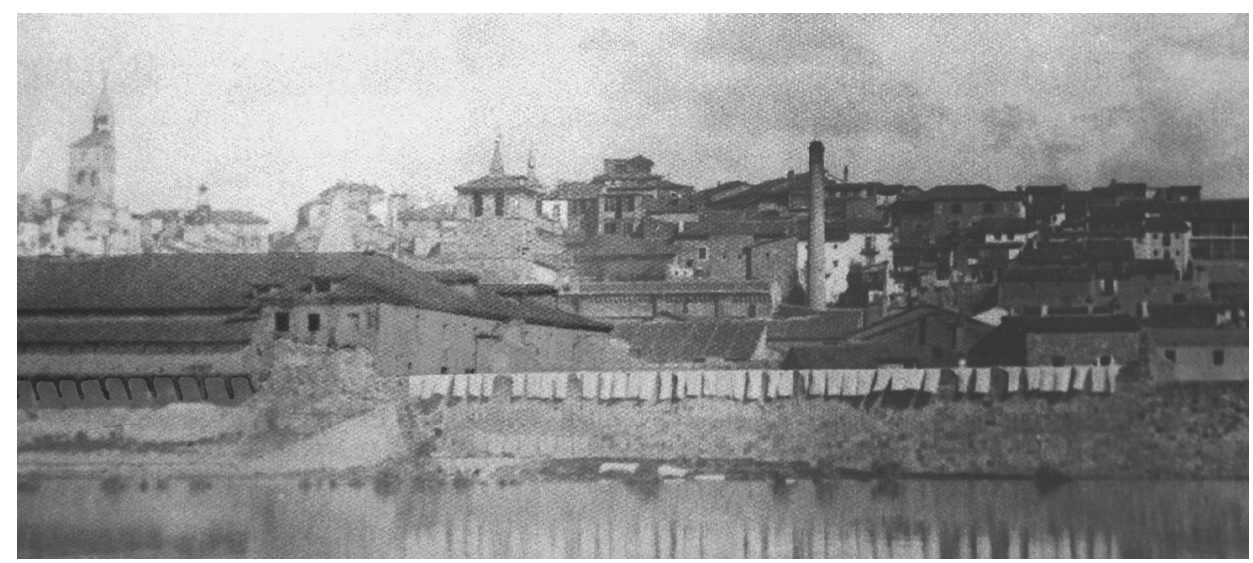

Fig. 3. Cuartel de Caballería desde la margen izquierda del Duero. Inicios del siglo XX (Detalle de la imagen extraída de Memoria gráfica de Zamora, La Opinión-El Correo de Zamora, 2000, p. 20). 


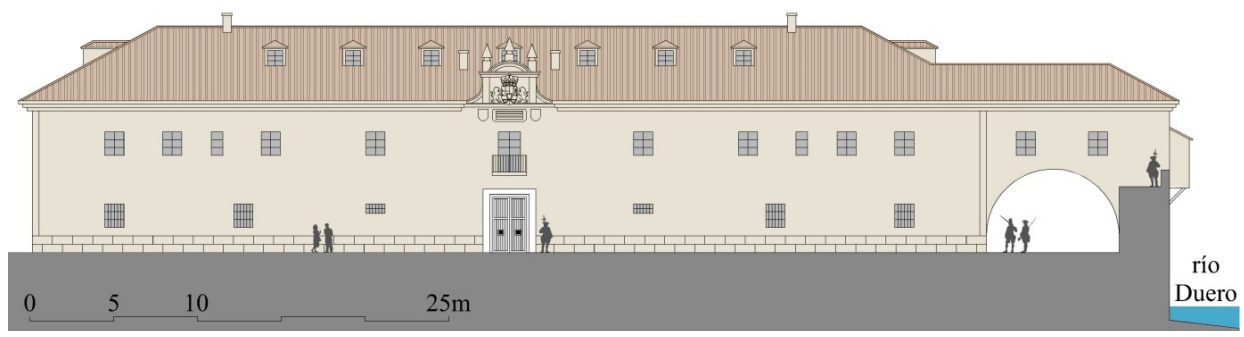

Fig. 4. Alzado principal del cuartel de Caballería (elaboración propia basándose en AGS, MPD, $X I-114$ y $X I-117)$.

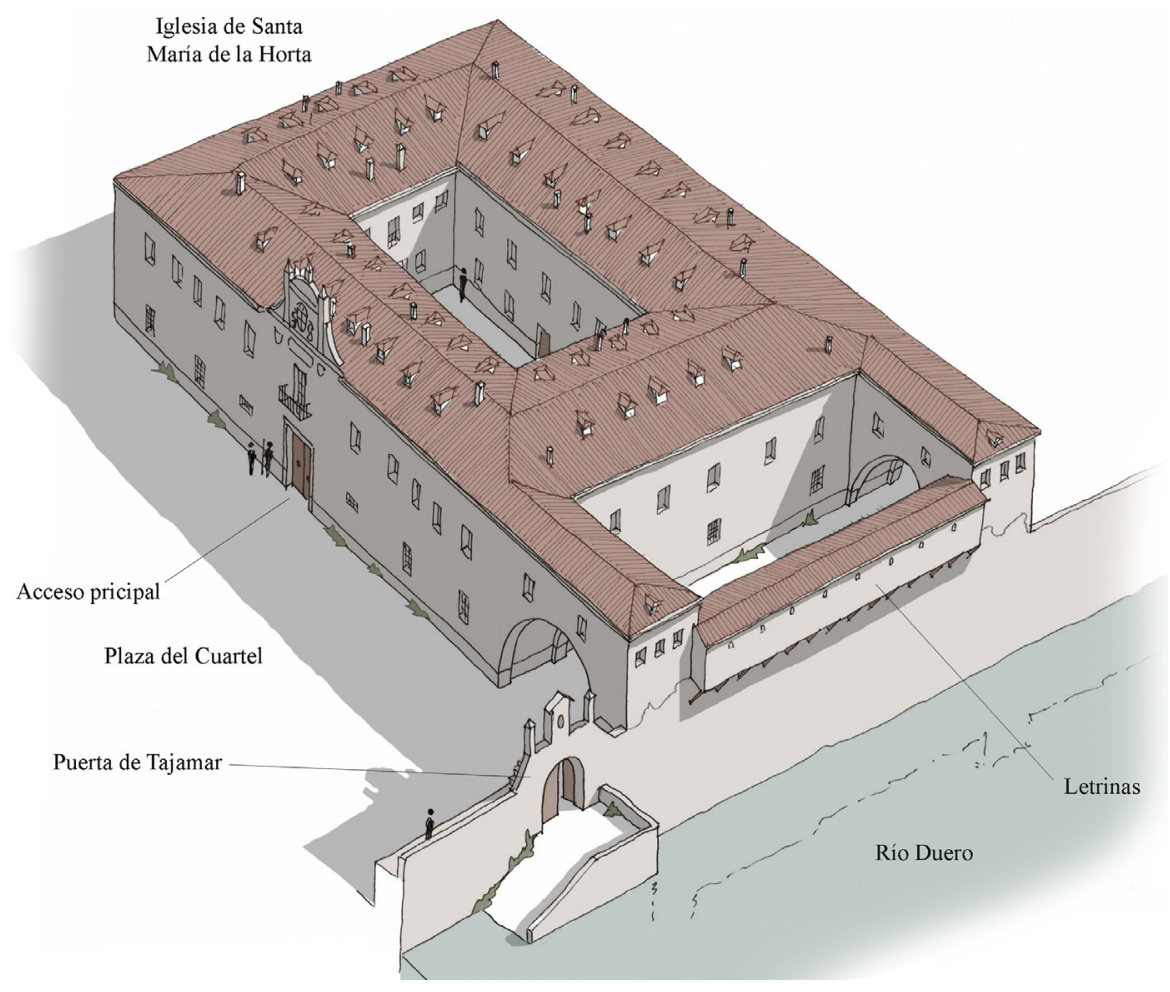

Fig. 5. Restitución del cuartel de Caballería (elaboración propia).

El cuartel de caballería era un edificio de planta central, con cuatro frentes alrededor de un patio con un pozo, del que no habría ningún problema de suministro, ya que tenía su boca a pocos metros por encima del nivel medio del río Duero. El 
DANIEL LÓPEZ BRAGADO Y VÍCTOR-ANTONIO LAFUENTE SÁNCHEZ LOS PROYECTOS DEL CUARTEL DE INFANTERÍA PARA LA CIUDAD DE ZAMORA EN EL PRIMER TERCIO DEL SIGLO XVIII

edificio estaba compuesto por dos plantas y bajocubierta, destinando la baja para caballerizas y las dos superiores como habitaciones para la tropa. Estos cuartos estaban distribuidos de forma homogénea, sin diferenciación para los oficiales, lo que a la larga fue un problema que persiguió al edificio.

Todo el cuartel estaba compuesto por dos crujías separadas por una arquería central. Cada crujía de caballerizas se organizaba mediante un pasillo con caballos a ambos lados, con una capacidad aproximada de quinientos veinte animales. Esta arquería se transformaba en muro en la planta primera, formando parte del pasillo perimetral que distribuía los dieciséis dormitorios comunales y otras estancias auxiliares con una capacidad aproximada de cuatrocientos soldados. De la planta bajocubierta solo se aprovechaba la zona central y de mayor altura, con dormitorios lineales que albergando en total a unos cien militares ${ }^{15}$. Dos corredores en los extremos del alzado sur conectaban el cuartel con las letrinas. Estos retretes se ubicaban en voladizo sobre la muralla con la ayuda de jabalcones de madera, para que evacuaran directamente sobre el río Duero. Como el adarve de la cerca estaba por debajo del suelo de la planta primera fue necesario disponer unas escaleras para descender a las letrinas.

El edificio contaba con dos accesos, uno septentrional, hacia la iglesia románica de Santa María de la Horta, regentada por las religiosas del convento de San Juan de Jerusalén, y otro occidental, que era el principal (Fig. 1). Este alzado oeste contaba con un zócalo de sillería sobre el que se dispondría un muro de mampostería revocado. La composición del alzado era simétrica respecto al eje de la puerta de acceso, salvo la bóveda de cañón del extremo sur que daba paso a las letrinas. Se trataba de una fachada austera debido a las carestías presupuestarias.

El acceso se realizaba mediante un portón sobre el que se dispondría una balconera, como era costumbre. Sobre ella se situaba una inscripción en piedra flanqueada por los escudos de las armas de la ciudad. Sobre este nivel, separado mediante una imposta, se dispondría un frontal con el escudo de las armas de Felipe V enmarcado por dos leones. La coronación se resolvía con un tímpano semicircular sobre el que se situaban tres pirámides de piedra. Las ventanas de la planta baja, que daban iluminación y ventilación a las cuadras, eran de pequeño tamaño, cerrándose con una reja. Las de la planta superior eran de mayor tamaño, aunque sin recercados ni elementos decorativos. Tan solo destacar la seriación de troneras en la cubierta para dar iluminación a los dormitorios del desván. Se desconoce la formalización del alzado norte, pero sería similar al oeste restándole los elementos decorativos sobre el acceso.

15. La ocupación de los dormitorios se ha llevado a cabo por medio de la reproducción de la cama tipo dibujada en otros planos del AGS. Se trata de un camastro de 2,00x1,40m, por lo que en cada lecho descansarían dos soldados.

Ediciones Universidad de Salamanca / అ@@ Stud. his., H. ${ }^{a}$ mod., 41, n. 1 (2019), pp. 407-433 


\section{DANIEL LÓPEZ BRAGADO Y VÍCTOR-ANTONIO LAFUENTE SÁNCHEZ LOS PROYECTOS DEL CUARTEL DE INFANTERÍA PARA LA CIUDAD DE ZAMORA EN EL PRIMER TERCIO DEL SIGLO XVIII}

Su financiación fue resuelta a costa de imponer a los zamoranos la tasa de treinta y dos maravedís al cántaro de vino y dos a la libra de carne. Estos arbitrios se mantuvieron para costear las reformas y el mantenimiento del edificio, el carbón para la luz y la calefacción, así como los faroles para las caballerizas. El coste de las obras debió ascender a 4.110 .326 reales de vellón ${ }^{16}$. Se construyó con álamo de Zamora y pino de Soria y Cuellar, teja y ladrillo de El Perdigón y piedra de las Enillas, El Perdigón y Zamora - Cuesta del Piñedo, El Postigo, Pinilla y la Fortaleza - . Los propios soldados ayudaron con la construcción, entre otras cosas con la extracción de la piedra ${ }^{17}$. En septiembre de 1704, Francisco Cid Pacheco ya había labrado los escudos de armas de la ciudad y la "piedra de las letras que se colocó en fachada» ${ }^{18}$. En esas mismas fechas, otro escultor, José Sánchez, talló el escudo Real y «los leones». Finalmente, en diciembre se emplomaban «las pirámides» del alzado principal ${ }^{19}$.

\section{EL CUARTEL DE CABALLERÍA NO ES SUFICIENTE}

En 1715 el conde de Ripalda ${ }^{20}$, gobernador de Zamora, describía:

Los cuarteles de Zamora son nuevos y muy cómodos, su fábrica permanece segura, sus caballerizas espaciosas y las cuadras alegres. Podía albergar a dos regimientos,

16. AGS, SGU, leg. 3285. Carta de 04.02.1715. La construcción del cuartel «emprendió una incesante actividad constructora en la ciudad». RUPÉREZ ALMAJANO, Ma Nieves: «Aspectos del urbanismo zamorano en el siglo XVIII. La junta de policía». En Actas del Primer Congreso de Historia de Zamora. Zamora, Diputación de Zamora, Instituto de Estudios Zamoranos Florián de Ocampo, tomo 4, 1991, p. 176.

17. Carrascal dirigió los trabajos de cantería, Antonio Machado (carpintero) y su hermano Santiago (sobreestante de carpintería) tenían a su cargo noventa y seis obreros (64 canteros y 32 carpinteros), sin contar sacadores, carreteros y otros oficios auxiliares. ALMARAZ VÁZQUEZ, Mercedes y BLANCO SÁNCHEZ, José Ángel: op.cit., p. 152.

18. La lápida de piedra bajo las armas reales decía «Año 1704. Reinando Su Católica Majestad de Felipe V, con acuerdo de Zamora se hizo esta obra, siendo gobernador D. Gonzalo Zegri de Salazar, sargento general de batalla. Comisarios D. Alonso López Cabeza de Vaca, D. Manuel Gómez Monje y D. Jerónimo Antonio de Ledesma». FERNÁNDEZ DURO, Cesáreo: op.cit., t. III, p. 83; CARRACEDO PRIMO, José E.: op.cit., p. 215.

19. AHPZa, MZa, leg. 1133-1, s/f 1704; En 1711 Barcia, su suegro y Machado cobraron el resto de su salario y parte de lo que se debía a los dos primeros por haber abastecido materiales. ALMARAZ VÁZQUEZ, Mercedes y BLANCO SÁNCHEZ, José Ángel: op.cit., p. 152.

20. ESTEBAN DE RIPALDA ( $(-1731)$ militar español, nombrado conde de Ripalda por Carlos II en 1699, caballero comendador de la Encomienda de Molinos y Laguna-Rota de la orden militar de Calatrava, fue nombrado gobernador civil y militar de Zamora en 1710. Nueve años después el rey le ascendió a brigadier y capitán general de los ejércitos del príncipe de Chelamar, residente en Salamanca, aunque en 1721 era aún gobernador, por lo que debió compatibilizar los dos cargos. Falleció en Sevilla. ALONSO DE CADENAS, Ampelio y DE CADENAS, Vicente: Elenco de grandezas y títulos nobiliarios españoles. Madrid, Hidalguía, 2002, p. 797.

Ediciones Universidad de Salamanca / 요 Stud. his., H. ${ }^{a}$ mod., 41, n. 1 (2019), pp. 407-433 
DANIEL LÓPEZ BRAGADO Y VÍCTOR-ANTONIO LAFUENTE SÁNCHEZ LOS PROYECTOS DEL CUARTEL DE INFANTERÍA PARA LA CIUDAD DE ZAMORA EN EL PRIMER TERCIO DEL SIGLO XVIII

uno de caballería y uno de infantería con todo desahogo, pero con estrecheces cabrían tres ${ }^{21}$.

Aunque Ripalda era conformista, lo cierto es que las hostilidades con el país vecino y la movilización de tropas continuaron, por lo que la capacidad del cuartel «de las Milicias» como se conocía popularmente, no era suficiente para esta actividad castrense. De hecho, ese mismo año hubo tantos heridos que el hospital zamorano de La Encarnación se saturó, derivando parte de los pacientes a las cuadras del cuartel, que habían sido habilitadas para tal fin ${ }^{22}$.

Los «parches» para albergar a la tropa aparecieron ya en 1711, momento que se conoce que Felipe González Tagarón había cobrado algunos reales por «los cuarteles que se hicieron en la puerta de San Pablo». Sin embargo, no debe llevar a engaño, ya que estas obras no debieron de representar más que la adaptación de casas para alojar a algunos soldados ${ }^{23}$. Por otro lado, dos años después la vecina ciudad de Toro ya contaba con un cuartel de Infantería con capacidad para un batallón, un cuartel de caballería para un regimiento y se estaban construyendo los cimientos de un tercer cuartel. Sin embargo, en Zamora solo albergaba un cuartel con capacidad para quinientos caballos y un regimiento de soldados, lo que resultaba escaso desde un primer momento.

\section{LA PROPUESTA DE UN CONJUNTO DE PEQUEÑOS PABELLONES}

Al no existir residencia para oficiales, éstos se alojaron en casas alquiladas en las inmediaciones del cuarte ${ }^{24}$. Para resolver definitivamente esta carestía residencial, en 1715 se planteó la oportunidad de rehabilitar a tal efecto unas casas del frente septentrional de la plaza del Cuartel. De hecho, la actuación era más ambiciosa, derivando en una operación urbanística que pretendía engalanar la plaza, alargando septentrionalmente la sede del Peso para crear un gran espacio público con soportales (Fig. 6) ${ }^{25}$.

21. AGS, SGU, leg. 3285, carta de 04.02.1715.

22. El corregidor Ripalda también informó de que la secretaría de Guerra mandó adquirir quinientas camas que costeó la Hacienda Real trayendo ropa (de cama) de Palencia. AGS, SGU, leg. 3285, carta de 04.02.1715.

23. Estos inmuebles eran propiedad de la cofradía de las Ánimas de San Salvador de la Vid alquiladas a tal efecto. ALMARAZ VÁZQUEZ, Mercedes y BLANCO SÁNCHEZ, José Ángel: op.cit., p. 153.

24. Para costeárse sus gastos se le otorgaba un dinero a cada oficial para el pago de la renta según su rango. AGS, SGU, leg. 3285, carta de febrero de 1713.

25. La memoria plantea el aprovechamiento máximo de los materiales de derribo, solo «aumentando su altura y hacer habitaciones» AGS, SGU, leg. 3285, carta de 04.02.1715.

Ediciones Universidad de Salamanca / అ@@ Stud. his., H. ${ }^{a}$ mod., 41, n. 1 (2019), pp. 407-433 
DANIEL LÓPEZ BRAGADO Y VÍCTOR-ANTONIO LAFUENTE SÁNCHEZ LOS PROYECTOS DEL CUARTEL DE INFANTERÍA PARA LA CIUDAD DE ZAMORA EN EL PRIMER TERCIO DEL SIGLO XVIII

Se desconoce cuando llegó a Zamora el teniente general, ingeniero director de las plazas de Castilla, marqués de Robelín ${ }^{26}$. La primera noticia data del 13 de febrero de 1721, momento en que le remitió al secretario de despacho de Guerra, José Patiño, marqués de Castelar, una carta en la que informaba que las tropas no estaban bien alojadas, ya que:

Hay mala distinción entre caballerizas y dormitorios. Existía mala disposición de camas tanto para el regimiento de Dragones como para el de Infantería, que estaban en él. Tanto los subterráneos del cuartel, como el almacén de víveres que se ha construido sobre la muralla, están a prueba de bombas, pero no a prueba de agua. El yeso de las bóvedas se cae por la humedad ${ }^{27}$.

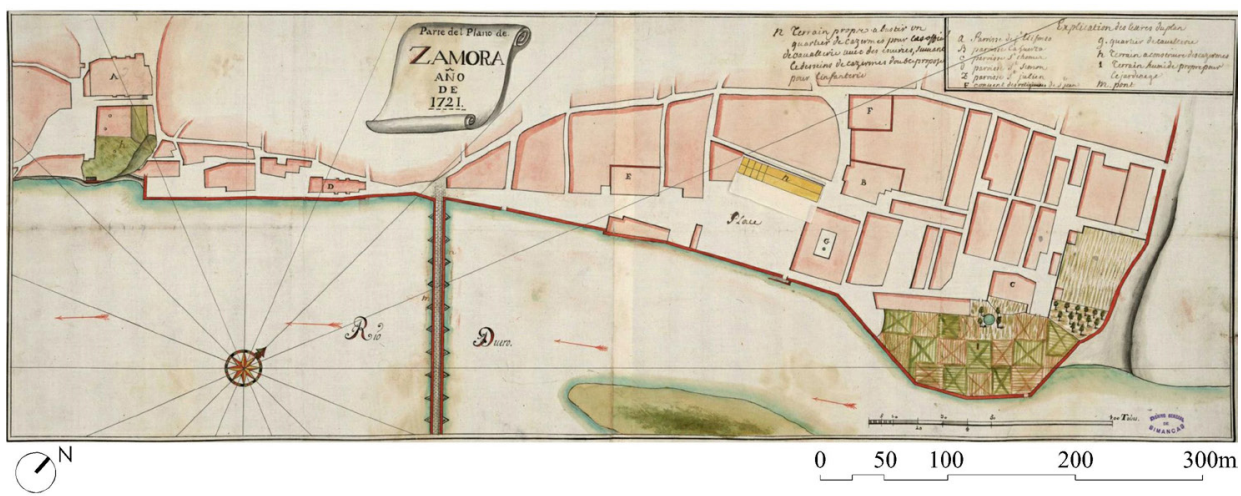

Fig. 6. Actuación integral en la plaza del Cuartel de Caballería. 1721 (AGS, MPD, XI-115).

El 11 de marzo el duque de Jovenazo, príncipe de Chelamar, nuevo gobernador de Zamora, envió una misiva a la Corona exponiendo que hasta el momento

26. CARLOS ROBELÍN (¿-?) marqués de Robelín, ostentando posteriormente el título de conde de Robelín (siendo el único ingeniero que ostentaba dicho título en el primer tercio del siglo XVIII), militar de origen francés, trasladado a España durante la Guerra de Sucesión Española, con el cargo ingeniero director de la Frontera de Castilla con residencia en Zamora desde finales de 1720 o inicios de 1721. Desde Zamora propuso la reorganización del cuerpo de ingenieros militares de España, con el fin de ponerlo en «estado de guerra». Proponía el establecer un cuarto cuerpo en el ejército junto al de infantería, artillería y marina. AGS, SGU, leg. 2998. Se trasladó a Ciudad Rodrigo en diciembre de 1721 por discrepancias con el gobernador de Zamora. En 1722 permanecía en el cargo, pero se desconocen nuevas noticias o sus nuevos destinos. DE LUIS CALABUIG, Ángel: Ciudad Rodrigo: las fortificaciones. Ciudad Rodrigo, ADECOIR, Ayuntamiento de Ciudad Rodrigo, 2009, p. 51.

27. AGS, SGU, leg. 3532, carta de 06.03.1721.

Ediciones Universidad de Salamanca / @®@@ Stud. his., H. ${ }^{a}$ mod., 41, n. 1 (2019), pp. 407-433 
DANIEL LÓPEZ BRAGADO Y VÍCTOR-ANTONIO LAFUENTE SÁNCHEZ LOS PROYECTOS DEL CUARTEL DE INFANTERÍA PARA LA CIUDAD DE ZAMORA EN EL PRIMER TERCIO DEL SIGLO XVIII

se había mantenido un «religioso silencio» por lo ahogado de la Hacienda Real, pero se veía en la obligación de informar que el cuartel de Zamora era para caballería, pero por «casualidad» permanecía establecido el segundo batallón de Infantería de África. El duque opinaba que habría que construir otro cuartel para infantería, así como una residencia para oficiales en la plazuela del Cuartel «que la hermoseara» ${ }^{28}$. Dos días más tarde, Carlos Robelín remitió a Madrid un proyecto de cuartel de infantería en el barrio de la Horta. La propuesta se situaba en las huertas del Cigarral, entre la iglesia de Santo Tomé y el rincón que generaba la muralla entre el Duero y las huertas de las Pallas extramuros de Puerta Nueva $(\text { Fig. } 1)^{29}$. Se pensó en esta ubicación por ser un vacío urbano intramuros, por lo que apenas era necesario derribar apenas «unas casitas que amenazaban ruina» ${ }^{30}$. Sin embargo, esta zona de la ciudad se había inundado en diversas ocasiones debido a las crecidas del Duero, que derribaban las puertas de la muralla hacia el río anegando la zona hasta la iglesia de la Horta. Estos sucesos desaconsejaban su utilización, además de que era conocedor de los problemas de humedad que presentaba el vecino cuartel de Caballería cuando tan solo contaba con diecisiete años de edad ${ }^{31}$.

La propuesta del ingeniero director estaba compuesta por cuatro pabellones que se adaptaban al perímetro irregular de la parcela. Constaba de dos tipologías de bloques: por un lado, pabellones de crujía estrecha, con escalera central que distribuía a dos dormitorios por planta; y, por otro lado, el pabellón de doble crujía, con escaleras dobles que distribuían dos estancias a cada lado. El proyecto de este tipo de pabellón tenía un error grave, ya que existían dormitorios que ventilaban y se iluminaban a través de un corredor que daba paso a otro dormitorio, lo que acarrearía malos olores desde el principio.

Estos pabellones estaban compuestos por tres plantas similares, sin aprovechamiento del desván. Cabe destacar los alzados, compuestos por un gran porcentaje de huecos recercados seriados por planta y separados por impostas horizontales (Fig. 8).

28. AGS, SGU, leg. 3285, carta de 11.03.1721.

29. AGS, SGU, leg. 3532, cartas de 13 y 22.03.1721. LARRÉN IZQUIERDO, Hortensia et alii: Fortificaciones abaluartadas de la provincia de Zamora. Valladolid: Junta de Castilla y León, 2010, p. 7.

30. AGS, SGU, leg. 3285, carta de 27.03.1721.

31. Desde Madrid se otorgaron 3.312 reales para los reparos del cuartel de Zamora. Este dinero sería gestionado por el intendente. AGS, SGU, leg. 3532, carta de 17.04.1721.

Ediciones Universidad de Salamanca / అ@@ Stud. his., H. ${ }^{a}$ mod., 41, n. 1 (2019), pp. 407-433 
DANIEL LÓPEZ BRAGADO Y VÍCTOR-ANTONIO LAFUENTE SÁNCHEZ LOS PROYECTOS DEL CUARTEL DE INFANTERÍA PARA LA CIUDAD DE ZAMORA EN EL PRIMER TERCIO DEL SIGLO XVIII

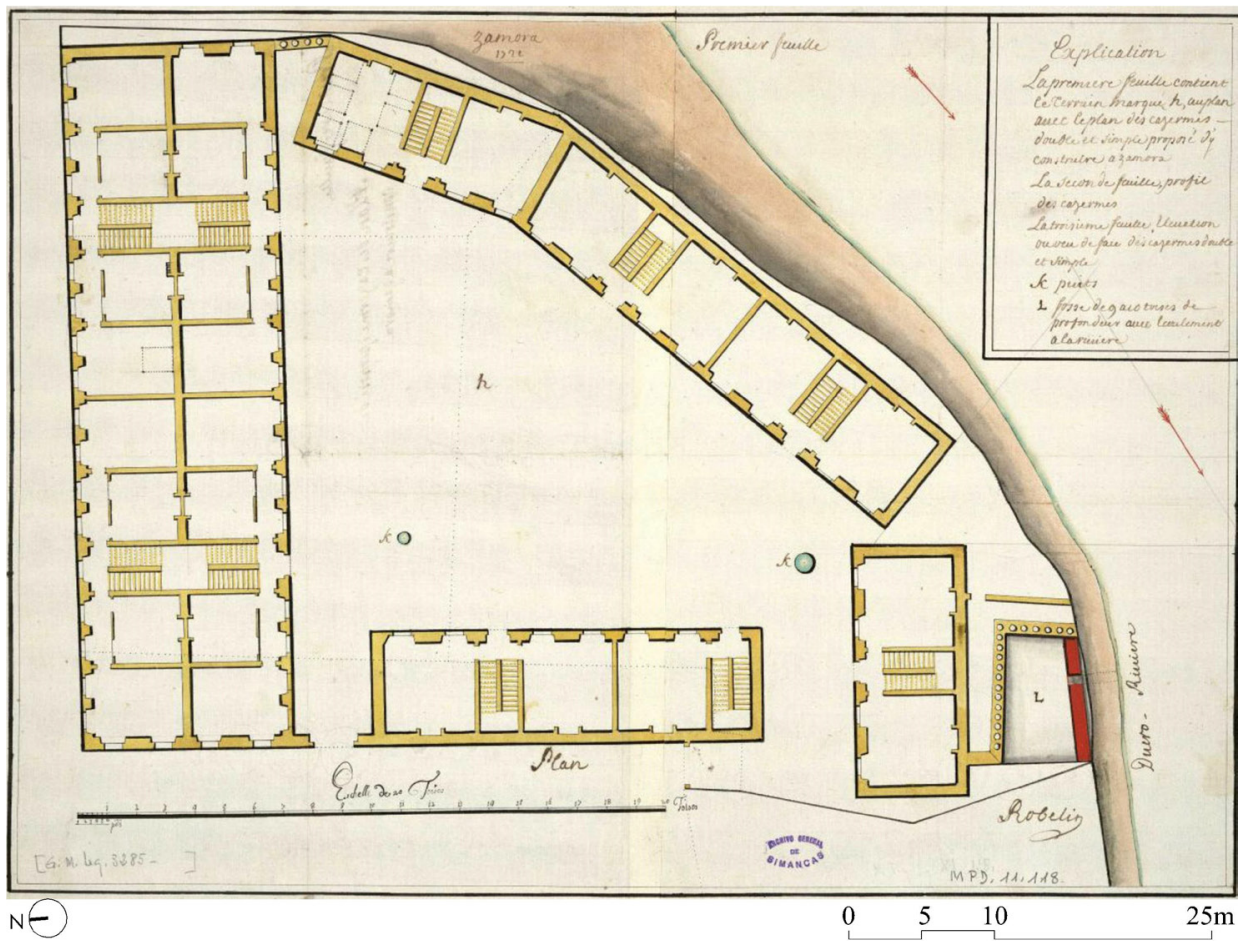

Fig. 7. Plano de planta del proyecto de cuartel de infantería. 1721. (AGS, MPD, XI-118 y XIII-98).

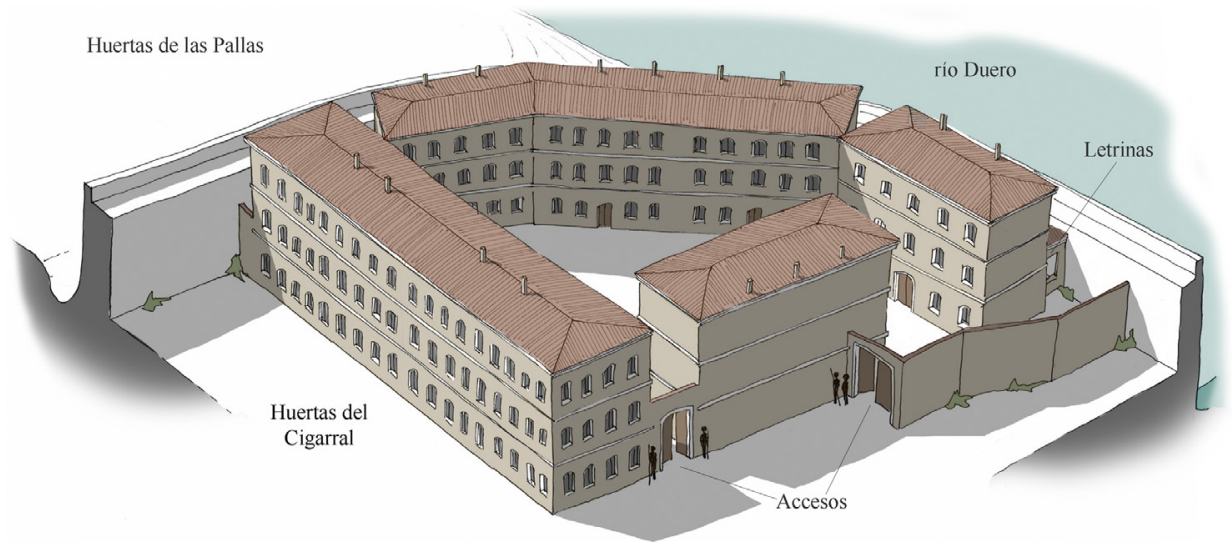

Fig. 8. Restitución del proyecto de cuartel de infantería de 1721 (elaboración propia).

Ediciones Universidad de Salamanca / 


\section{DANIEL LÓPEZ BRAGADO Y VÍCTOR-ANTONIO LAFUENTE SÁNCHEZ LOS PROYECTOS DEL CUARTEL DE INFANTERÍA PARA LA CIUDAD DE ZAMORA EN EL PRIMER TERCIO DEL SIGLO XVIII}

Pasaron los meses de primavera y verano sin avances, hasta que el 28 de octubre de 1721, Carlos Robelín informó al marqués de Castelar de la causa de esta inactividad. Al parecer, se originaron desavenencias personales entre el gobernador de Zamora, brigadier conde de Ripalda y el ingeniero, lo que originó el traslado de éste último por voluntad propia a Ciudad Rodrigo y la paralización del proyecto ${ }^{32}$.

Desde esa ciudad salmantina, el 27 de marzo del año siguiente, el ingeniero Robelín llevó a cabo la recopilación de los trabajos que serían necesarios para reparar el cuartel de Caballería y el proyecto de construcción del de Infantería. Se la envió al marqués de Castelar, para que a su vez se la planteara a la Real Junta de Fortificaciones. Para ello elaboró una memoria, un presupuesto y una serie de planos en los que abordaba básicamente tres proyectos:

- Por un lado, representó la planta baja y el alzado principal del cuartel de Caballería, donde se llevarían a cabo actuaciones de reparación. Estas medidas eran básicamente dos. Primero rasgar verticalmente y ensanchar las ventanas de las caballerizas de planta baja para una mejor iluminación y ventilación (Hay que tener presente que la diferencia de cota entre el nivel normal del río y el suelo de tierra de las caballerizas no superaría el metro y medio). Por otro lado, se planteaba empedrar el perímetro embarrado del cuartel, de este modo, originando una caída de las aguas hacia el exterior de los márgenes del edificio se evitaban humedades producidas por las escorrentías del tejado ${ }^{33}$.

- Robelín representó la ubicación de la residencia de oficiales en el frente septentrional de la plazuela del cuartel «de las Milicias», proyecto que había nacido en 1715 (Fig. 6) ${ }^{34}$.

- Por último, volvió a presentar el proyecto de acuartelamiento para un batallón y un escuadrón de Infantería en las huertas del Cigarral mediante pabellones independientes que se adaptaban a la forma de la parcela ${ }^{35}$.

La contestación no se hizo esperar, y a principios de abril, el jefe de la Junta de Fortificaciones, Jorge Próspero Verboom, respondió a Carlos Robelín sobre las tres propuestas ${ }^{36}$. En primer lugar, aprobó los «reparos» planteados para mejorar la

32. Ibidem, cartas de 28.10.1721 - 12.11.1721 - 28.11.1721 - 02.12.1721.

33. Los planos son respectivamente. AGS, MPD, XI-116 y AGS, MPD, XI-117. La memoria y el presupuesto en francés se puede consultar en AGS, SGU, leg. 3285, carta de 27.03.1722.

34. AGS, MPD, XI-115 y su copia XIII-101.

35. El proyecto estaba compuesto por la planta baja, la sección y el alzado septentrional del pabellón tipo. Los planos son respectivamente AGS, MPD, XI-118; XI-119 y XI-120.

36. En marzo de 1721, Verboom emprendió un viaje por las plazas españolas, se encontraba en Málaga cuando mandó la misiva a Robelín. AGS, SGU, leg. 3532, carta de 10.04.1721. Jorge Próspero Verboom (1665-1744) hijo de Cornelio Verboom, Ingeniero General de los Países Bajos, heredó el cargo de su padre en 1692 con 27 años de edad. Ascendido a brigadier en 1702 y

Ediciones Universidad de Salamanca / @@@ Stud. his., H. ${ }^{a}$ mod., 41, n. 1 (2019), pp. 407-433 
DANIEL LÓPEZ BRAGADO Y VÍCTOR-ANTONIO LAFUENTE SÁNCHEZ LOS PROYECTOS DEL CUARTEL DE INFANTERÍA PARA LA CIUDAD DE ZAMORA EN EL PRIMER TERCIO DEL SIGLO XVIII

habitabilidad del cuartel de Caballería. Pero a Verboom no le agradó la distribución de los cuartos y el modo de construcción del nuevo cuartel de Infantería, ya que «estaba concebido a la antigua, (...) según la práctica aprobada por el difunto mariscal de Vauban (...) a las habitaciones les faltan aire» ${ }^{37}$. Por ejemplo, los dormitorios eran más bajos de los que se estaban construyendo en otras plazas. La fachada no tenía simetría ni «buena vista», refiriéndose a la escasa altura de las ventanas. Por último, hacía referencia a lo reducido de los dormitorios y a la escasa dimensión de las camas dibujadas, en las que no entraría holgadamente un soldado ${ }^{38}$. Este escrito del principal ingeniero militar del país provocaría una nueva paralización del proyecto de construcción del cuartel de Infantería.

\section{EL PAJAR DEL REY}

Las cuadras de la planta baja del cuartel de Caballería albergaban a un gran número de caballos que eran abastecidos con paja y grano almacenados en inmuebles tan dispares como la Alhóndiga Mayor y Menor, el Patio de Comedias o el «almacén de San Miguel», todos ellos distantes del cuartel al que daban servicio ${ }^{39}$. El paso constante de carros tirados por caballerías por las principales vías que los conectaban, como la cuesta de Balborraz o la del Piñedo, originaban numerosos accidentes debido a la pendiente de las mismas y su mala conservación. Esta precaria situación provocó que el Consistorio solicitara en agosto de 1732 a José de Barcia la mejor ubicación y las trazas de un pajar próximo al cuartel. Se eligió el inmueble que ocupaba el Peso Real, junto a las pescaderías, anexo a la muralla y en frente del acuartelamiento de Caballería (Fig. 1).

mariscal de campo en 1704. Tras la pérdida de los Países Bajos, fue trasladado a España en 1709 por los apuros de Felipe V en la Guerra de Sucesión Española. Ante una posible invasión inglesa por Portugal, Verboom examinó la frontera extremeña y en 1910 fue nombrado «Ingeniero General de los ejércitos, plazas y fortificaciones de todos los Reinos, Provincias y Estados de la Corona». Desde ese momento tuvo el poder de decisión de las ciudades que se fortificaban, el nombramiento de los ingenieros, sus destinos y organización de los mismos, estando en el cargo hasta su muerte en 1744, dos años antes de la de su rey. MUÑOZ CORBALÁN, Juan Miguel: Jorge Próspero Verboom. Ingeniero militar flamenco de la monarquía bispánica. Madrid, Fundación Juanelo Turriano de Historia de la Ingeniería, 2015.

37. AGS, SGU, leg. 3532, carta de 10.04.1721.

38. AGS, SGU, leg. 3532, carta de 10.04.1721.

39. AHPZa, MZa, actas 1731, f. 101v; ALMARAZ VÁZQUEZ, Mercedes y BLANCO SÁNCHEZ, José Ángel: op.cit., p. 166. Se le daba media arroba de paja por caballo. AGS, SGU, leg. 3285, carta de 04.02.1715. 

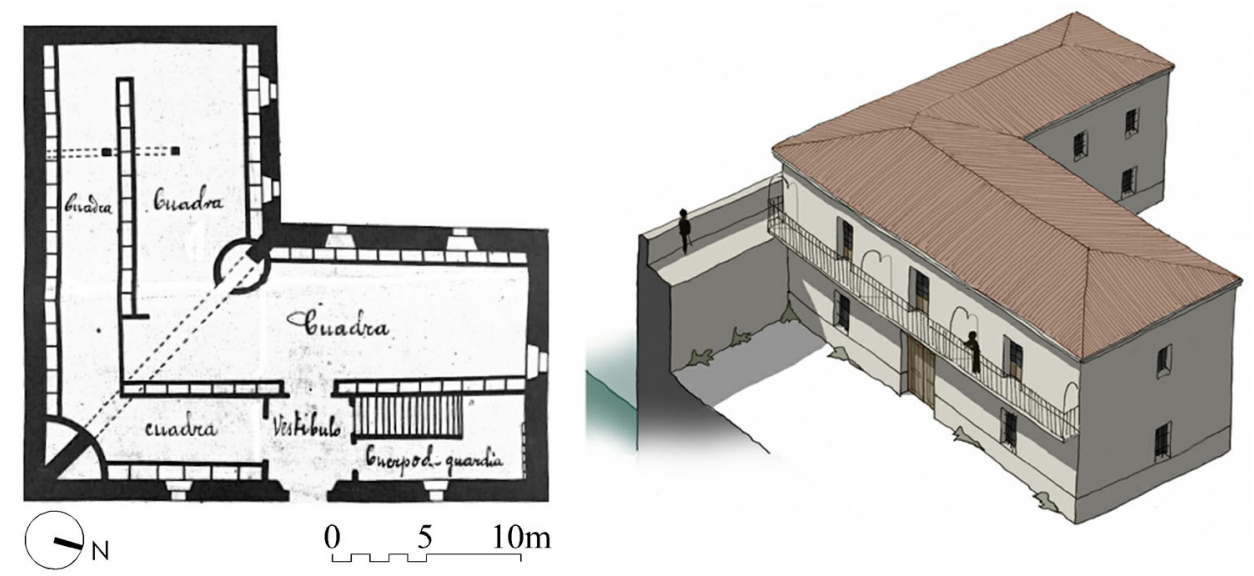

Fig. 9. Planta y restitución del Pajar del Rey. La planta pertenece a AHPZa, Hacienda, 40 (provisional). Incluida en Mercedes ALMARÁZ VÁZQUEZ y José Ángel BLANCO SÁNCHEZ: op.cit., p. 166.

Se trataba de un edificio de pequeñas proporciones en forma de $\mathrm{L}$ y con dos plantas. El nivel inferior, destinado a albergar caballos, estaba organizado en una crujía. Mediante una escalera próxima al acceso se ascendía a la planta alta que albergaba la paja y el grano, separada de la temida humedad del suelo procedente del río.

De su construcción se encargó Pedro Pérez por 37.000 reales. En abril de 1733 se formalizó la fianza y de inmediato comenzaron las obras ${ }^{40}$. Detrás del pajar, junto a la muralla estaban las «casas del pescado», que fueron trasladadas a otro lugar en septiembre del año siguiente, evitando olores y enfermedades que pudieran contagiar a los animales ${ }^{41}$. La disposición original del edificio fue modificada pocos meses después, cuando José de la Fuente, comisario de la fábrica del pajar, opinó que era pequeño, aunque en verdad deseaba una ampliación del balcón para que albergara a mayor número de asistentes para contemplar los festejos que se llevaban a cabo en la plazuela del Cuartel, siendo los encierros de novillos los de mayor atracción ${ }^{42}$.

40. El cabildo protestó porque los escombros procedentes de los derribos se arrojaban al río, perjudicando a sus aceñas aguas abajo. Archivo Catedralicio de Zamora, lib. Manus, 133 , f. 294v, 02-08-1733.

41. Se utilizaron 3.000 reales para su compra y derribo. MUÑOZ MIÑAMBRES, José: Op.cit., p. 81.

42. Esta ampliación fue tasada por Barcia en 5.000 reales. AHPZa, MZa, actas 1734, f. 77v. En 1735 valoraría en otros 35.210 reales las mejoras efectuadas por Pedro Pérez, lo que duplicaba el presupuesto inicial. ALMARAZ VÁZQUEZ, Mercedes y BLANCO SÁNCHEZ, José Ángel: op.cit., p. 165.

Ediciones Universidad de Salamanca / అ@@ Stud. his., H. ${ }^{a}$ mod., 41, n. 1 (2019), pp. 407-433 
DANIEL LÓPEZ BRAGADO Y VÍCTOR-ANTONIO LAFUENTE SÁNCHEZ LOS PROYECTOS DEL CUARTEL DE INFANTERÍA PARA LA CIUDAD DE ZAMORA EN EL PRIMER TERCIO DEL SIGLO XVIII

\section{LA CONSTRUCCIÓN DEL CUARTEL APROVECHANDO EL PAJAR DEL REY}

En septiembre de 1735 llegó a Zamora el regimiento de Dragones de la Reina, lo que obligó a desalojar a las milicias de Toro del cuartel de Caballería. Estos milicianos se dispersaron ocupando casas, templos y caballerizas, lo que generó desorganización e indisciplina ante los oficiales, desencadenando algunas deserciones ${ }^{43}$.

Este aumento de tropas en la ciudad, y la incapacidad de albergarlas a todas en el cuartel de Caballería condujo al gobernador civil y militar de Zamora, Ginés de Hermosa $^{44}$, a solicitar al regidor Fernando Villafañe y Balanza que encargara unos planos de un nuevo cuartel de Infantería a Juan Sobrino y el presupuesto estimativo del mismo a José de Barcia, ambos maestros de obras ${ }^{45}$.

El plano no se conserva, pero la idea inicial era aprovechar el Pajar del Rey, finalizado ese mismo año, para ampliarlo mediante un pabellón alargado frente a la iglesia de San Julián (Fig. 1). Para resolver su financiación el consistorio propuso restablecer la tasa al cántaro de vino tinto y a la libra de carne de vaca y carnero, como se había venido haciendo hasta 1727 . Por último, solicitó a la superintendencia la obligatoriedad de que la tropa colaborara en las tareas de construcción del cuartel ${ }^{46}$.

En noviembre de ese mismo año de 1735, el Consistorio aprobó el proyecto, y el gobernador solicitó a José Patiño la construcción de un cuartel con capacidad para mil infantes en Zamora ${ }^{47}$. Esta gestión generó una correspondencia a tres bandas entre el gobernador Ginés de Hermosa, el secretario de Estado José Patiño y el presidente del Consejo de Castilla, monseñor Gaspar de Molina y Oviedo ${ }^{48}$. Tras

43. AGS, SGU, leg. 3532, carta de 28.11.1736.

44. GINÉS DE HERMOSA Y ESPESO fue un militar español, brigadier de caballería, gobernador de civil y militar de Zamora desde 1735, ascendido a asistente de Sevilla e intendente del ejército de Andalucía. MUÑOZ MIÑAMBRES, José: op.cit., p. 86.

45. El coste estimado por José de Barcia era de 297.388 reales. Este arquitecto también tasó las casas inmediatas al Pajar del Rey, ya que era necesaria su adquisición y derribo para la construcción del nuevo cuartel. El pleno tuvo lugar del día 19 de noviembre. AGS, SGU, leg. 3532, carta de 26.11.1735.

46. De igual modo de lo que ocurría en Ciudad Rodrigo.

47. El día 12 de ese mes, José de Barcia elaboró un presupuesto del cuartel. En él se describe las casas a adquirir y derribar. Por un lado la casa propia del común y pobres de esta ciudad que antes se utilizaba para remozar el pescado, de 24 pies de frente y 32 pies de fondo sin incluir el grueso de la muralla, valorada en 2.688 reales aprovechando madera y tejas. La casa de Margarita Villaverde de 92 pies de frente y 32-35 pies de fondo, valorada en 9.626 reales. Por último la vivienda de Ana María de Santa María de 64 pies de frente y 33 de fondo, valorada en 4.224 reales. AGS, SGU, leg. 3532, carta de 12.11.1735; Ídem, carta de 27.04.1737.

48. GASPAR DE MOLINA Y OVIEDO (1679-1744) fue un religioso emeritense obispo de Santiago de Cuba, Barcelona y Málaga, ascendiendo finalmente al cardenalato. Pero su verdadero trabajo estuvo al frente de la presidencia del Consejo de Castilla desde 1733 hasta

Ediciones Universidad de Salamanca / 요 Stud. his., H. ${ }^{a}$ mod., 41, n. 1 (2019), pp. 407-433 
DANIEL LÓPEZ BRAGADO Y VÍCTOR-ANTONIO LAFUENTE SÁNCHEZ LOS PROYECTOS DEL CUARTEL DE INFANTERÍA PARA LA CIUDAD DE ZAMORA EN EL PRIMER TERCIO DEL SIGLO XVIII

meses de burocracia entorno a la financiación de la operación, Ginés, en una carta dirigida a Patiño, le informó en abril de 1736, que los dragones de la Reina habían abandonado Zamora, pero habían dejado infectado de sarna y muermo el cuartel de Caballería, por lo que no podrían realojar a las milicias toresanas en dicho edificio ${ }^{49}$.

Ante la gravedad de la situación y la evidente necesidad de un segundo cuartel, el rey aprobó el 4 de junio de 1736 el Real decreto para la construcción de un cuartel en Zamora y la concesión de tres arbitrios para financiarlo ${ }^{50}$. Sin embargo, cuatro días después, Patiño le informó a Ginés que el ingeniero director Pedro Moreau ${ }^{51}$ tendría que llevar a cabo unas modificaciones solicitadas por la Junta de Fortificaciones ${ }^{52}$. Casi un año después, el 15 de mayo de 1737, Ginés de Hermosa envió al duque de Montemar, recién nombrado secretario de despacho de Guerra, una carta en la que le exponía la sobreocupación del cuartel de Caballería que obligaba a alojar tropas en casas particulares con el gasto municipal que acarreaba y las dificultades para mantener la disciplina de la tropa ${ }^{53}$.

su fallecimiento. La correspondencia entre Ginés de Hermosa, José Patiño y Gaspar de Molina tuvo lugar a lo largo de los días 14 de diciembre, 22 y 24 de enero de 1736, 5 de febrero, 10 de marzo y 15 de abril. Todas ellas en AGS, SGU, leg. 3532.

49. AGS, SGU leg. 3532, carta de 11.04.1736.

50. AGS, SGU, leg. 3532, carta de 27.04.1737; Se hace referencia a dicho documento en Ídem, carta de 20.11.1736.

51. PEDRO MOREAU (1694-c.1760) oriundo de la ciudad francesa de Bayona, en 1711 pasó a España como ingeniero voluntario en la Guerra de Sucesión Española. Entre otros destinos actuó en el sitio de Barcelona, participando en la construcción de la ciudadela de la dicha ciudad una vez tomada. Se especializó en fortificaciones y en reconocimiento de plazas fuertes, por lo que sería nombrado ingeniero ordinario (teniente de infantería) y en 1718 ingeniero segundo (capitán). Trabajó en Burgos, Bilbao, San Sebastián y Fuenterrabía, con lo que en 1722 pasó al cargo de teniente coronel. En Pamplona, por orden de Verboom, fue nombrado ingeniero jefe en 1726. Tras distintos destinos, pasó dos años a Ciudad Rodrigo, donde sería el ingeniero jefe de la Frontera de Castilla y el director de las obras del fuerte de la Concepción, en la Aldea del Obispo. En 1747 pasó a brigadier. Tras un paso por Cádiz, regresó a Zamora en 1750 hasta 1753, siendo el director de las obras del cuartel de esta ciudad. En 1756 pidió su ascenso a mariscal de campo, mérito que obtuvo aunque se desconoce cuándo (En 1767, Julián Giraldo de Chaves que le sustituiría en el cargo de ingeniero director, se refirió a él como mariscal de campo. AGS, SGU, leg. 3300, carta de 11.04.1767). En 1761 escribió desde Zamora sus opiniones sobre la logística portuguesa, ciudad donde se cree que falleció. MANZANO MONIS, Manuel: «El Mariscal de Campo D. Pedro Moreau y el Fuerte de la Concepción», en Academia, Boletín RABASF. Madrid, Real Academia de Bellas Artes de San Fernando, no 52, 1981, pp. 201-249.

52. AGS, SGU, leg. 3532, carta de 27.04.1737.

53. En palabras de Ginés de Hermosa. Éste decía estar en posesión de 1.230 .900 reales para ejecutar el cuartel. AGS, SGU, leg. 3532, carta de 15.05.1737. De hecho, en 1741 se derribaría el atrio de la iglesia de Santa María de la Horta debido a los actos impúdicos que se llevaban a cabo allí. MARTIIN BAILÓN, Marco-Antonio y PÉREZ MARTÍN, Sergio (coord.): «Comentarios a la lámina 42» en Zamora año de 1850: cuaderno de vistas de Zamora tomadas del natural y ejecutadas por Don José Ma Avrial y Flores. Zamora, Real Academia de Bellas Artes de San

Ediciones Universidad de Salamanca / 요 Stud. his., H. ${ }^{a}$ mod., 41, n. 1 (2019), pp. 407-433 
DANIEL LÓPEZ BRAGADO Y VÍCTOR-ANTONIO LAFUENTE SÁNCHEZ LOS PROYECTOS DEL CUARTEL DE INFANTERÍA PARA LA CIUDAD DE ZAMORA EN EL PRIMER TERCIO DEL SIGLO XVIII

Finalmente, casi un año después, el 1 de junio de 1737 Moreau envió «dos proyectos». Por un lado, corregía la propuesta del cuartel sobre el reciente Pajar del Rey; y por otro, el que ya se estaba fraguando por iniciativa del gobernador de la ciudad, que estimaba que era mejor dejar el Pajar con su uso y construir un cuartel de Infantería aledaño al de Caballería ${ }^{54}$. Moreau argumentaba que, aunque el Pajar del Rey se había quedado pequeño porque solo podía contener 20-25.000 arrobas de paja, éste era necesario, ya que el cuartel de caballería no contaba con pajar propio, ni cuerpo de guardia para la oficialidad.

La propuesta de aprovechar el Pajar del Rey para el nuevo cuartel planteaba un gran pabellón de dormitorios que se distribuían por un corredor cerrado con una seriación de arcos de medio punto en la fachada meridional. Las escaleras que daban acceso a la planta superior se disponían en el patio sur, junto al corredor, situando unas pequeñas letrinas en los extremos de dicho patio (Fig. 10 superior). Por lo demás, la propuesta mejorada del mismo autor y del mismo año mantenía la disposición general, pero el acceso se produciría justo en frente del atrio de la iglesia de San Julián, originando un vestíbulo flanqueado con dos escaleras de tres tramos. El patio se reducía con la generación de una segunda arquería que cubría las letrinas y las cocinas (Fig. 10 centro). Trece años después, otro técnico, Francisco Llovet, volvería a rediseñar la posibilidad de construir un cuartel aprovechado el Pajar del Rey. En este caso el complejo contaba con tres plantas y bajocubierta con troneras (Fig. 10 inferior y 11). El proyecto era similar a la última propuesta de Moreau, a la que completaba con un patio interior junto al Pajar, cuatro núcleos de escaleras - que marcaban la verticalidad del edificio - , aprovechando el Pajar para albergar las estancias de los oficiales y, por último, retomando la idea inicial de acceder al edificio por la propia puerta del Pajar situada en la plazuela de las Milicias.

Medio mes después del envío de Moreau, el duque de Montemar le contestó con distintas incidencias sobre el proyecto de aprovechamiento del Pajar. La primera y más importante era que la propuesta solo tenía capacidad para alojar a un batallón, y la regla era hacerlo para dos o más batallones, es decir, unos mil doscientos soldados. Apuntó que podría ser el momento de regularizar la plazuela del Cuartel y que el edificio contara con una sola entrada con un cuerpo de guardia. Argumentó que el cobertizo de las «secretas» - retretes - y cocinas necesitaban «desaguadero al río», ya que, en opinión de Leandro Bachelieu ${ }^{55}$, ingeniero residente en la ciudad,

Fernando, Ayuntamiento de Zamora, Diputación de Zamora, Instituto de Estudios Zamoranos Florián de Ocampo, Imprenta Jambrina, 2013, p. 254.

54. AGS, SGU, leg. 3532, carta de 01.06.1737; AGS, MPD, XXXIX-49; XXVII-45; XXXIX-50 y XXXIX-51.

55. LEANDRO BACHELIEU ( ${ }^{-}$-?) militar francés, ingeniero segundo del ejército español desde 1726. Entre otros cometidos participó en el trazado de los jardines de la Granja de San Ildefonso, desde donde fue llamado a sustituir temporalmente a su compatriota Esteban

Ediciones Universidad de Salamanca / @@@ Stud. his., H. ${ }^{a}$ mod., 41, n. 1 (2019), pp. 407-433 
DANIEL LÓPEZ BRAGADO Y VÍCTOR-ANTONIO LAFUENTE SÁNCHEZ LOS PROYECTOS DEL CUARTEL DE INFANTERÍA PARA LA CIUDAD DE ZAMORA EN EL PRIMER TERCIO DEL SIGLO XVIII
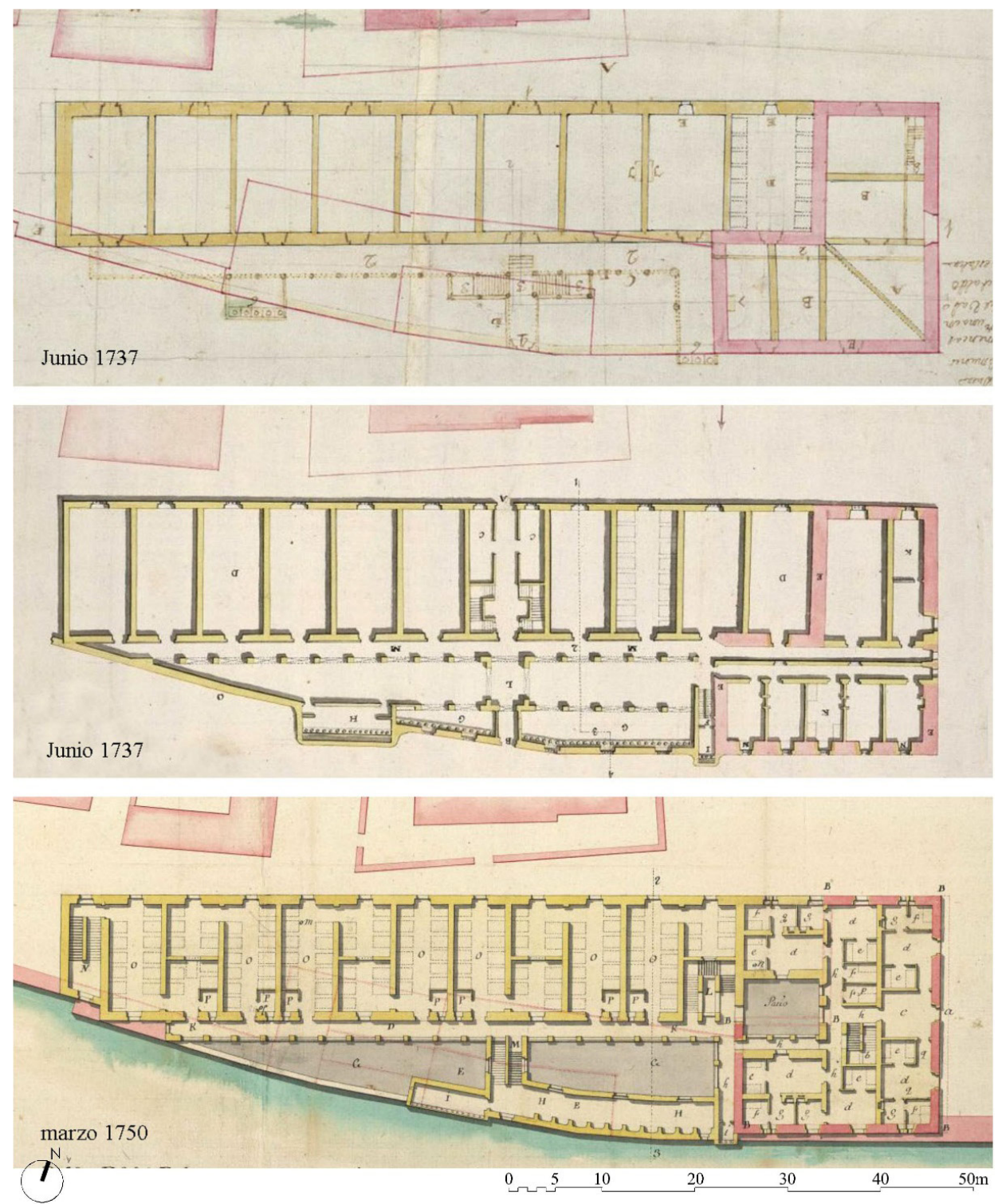

Fig. 10. Proyectos de cuartel aprovechando el Pajar del Rey. (Detalles de los planos AGS, MPD, $X X X I X-50, X X V I I-45$ y XXXIX-49 respectivamente). 


\section{DANIEL LÓPEZ BRAGADO Y VÍCTOR-ANTONIO LAFUENTE SÁNCHEZ LOS PROYECTOS DEL CUARTEL DE INFANTERÍA PARA LA CIUDAD DE ZAMORA EN EL PRIMER TERCIO DEL SIGLO XVIII}

con pozos no sería suficiente ${ }^{56}$. Por último, se aconsejaba situar las cocinas en el patio, alejadas de los dormitorios para evitar incendios ${ }^{57}$. En otra carta posterior, Montemar solicitó a Moreau que el proyecto que estaba redactando contuviera unos alojamientos para los oficiales del cercano cuartel de Caballería ${ }^{58}$.

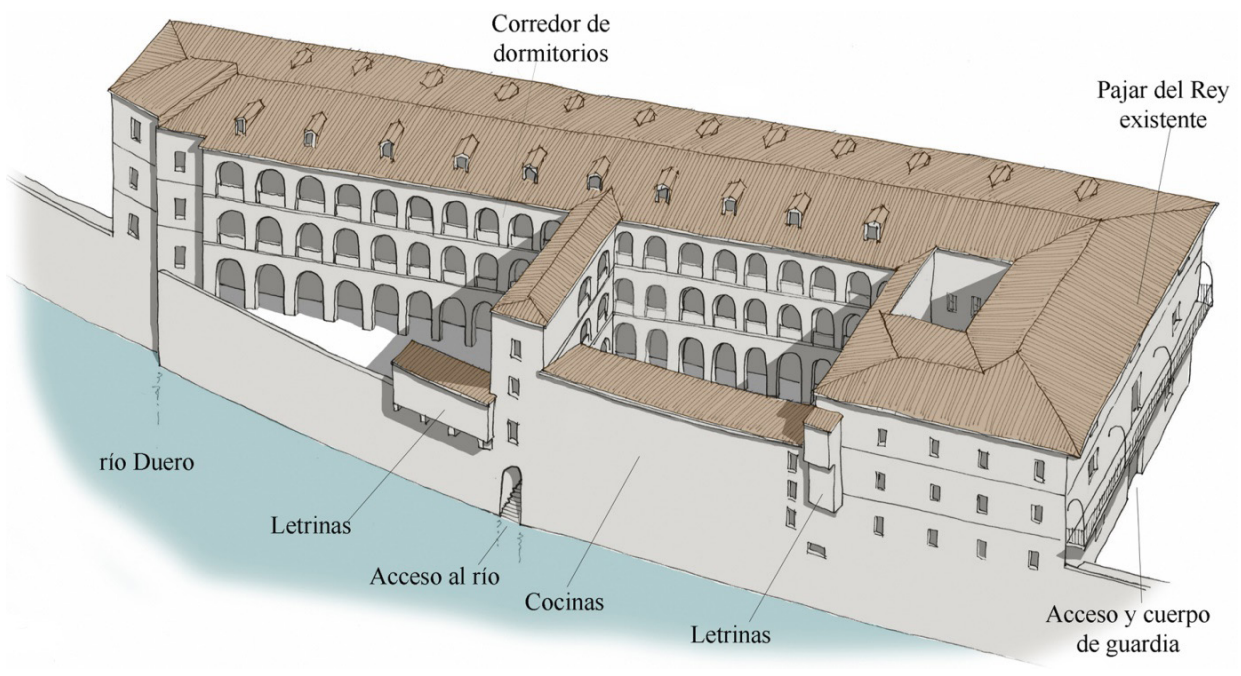

Fig. 11. Restitución del proyecto del cuartel sobre el Pajar del Rey. Propuesta de 1750 (elaboración propia basándose en $A G S, M P D, X X X I X-49)$.

Marchand en julio de 1733 al frente a las obras del palacio de Aranjuez. Ese mismo año falleció Marchand, quedándose como director de las obras. Al parecer Bachelieu era un hombre problemático, ya que estuvo enfrentado con su predecesor Marchand, con el director de los jardines de Aranjuez, Esteban Boutelou y con el gobernador Samaniego, corregidor de Aranjuez. Ante esta situación Bachelieu el día antes de la nochebuena de 1734 pidió trasladarse a Madrid "para la ejecución de las amenazas, pues estoy harto de disgustos». Se desconoce sus destinos antes de su estancia en Zamora desde 1738 hasta 1739 que fue trasladado a La Coruña. En la ciudad estuvo como ingeniero segundo con el grado de capitán, y realizó el proyecto del cuartel de infantería en las cortinas de San Miguel en 1738. Se conoce que en 1745 estuvo destinado en Ceuta y en 1750 en Toro. TOVAR MARTÍN, Virginia: «Esteban Marchand y Leandro Bachelieu, ingenieros franceses en las obras del Real Sitio de Aranjuez». En Anales de historia del arte. Madrid, Universidad Complutense de Madrid, nº8, 1998, pp. 291-308.

56. AGS, SGU, leg. 3533, carta de 12.01.1738. El dos de enero sería enviado a la Real Junta de Fortificaciones Idem, carta de 22.01.1738.

57. AGS, SGU, leg. 3532, carta de 19.06.1737.

58. Ídem, leg. 3532, carta de 02.07.1737.

Ediciones Universidad de Salamanca / @®@@ Stud. his., H. ${ }^{a}$ mod., 41, n. 1 (2019), pp. 407-433 
DANIEL LÓPEZ BRAGADO Y VÍCTOR-ANTONIO LAFUENTE SÁNCHEZ LOS PROYECTOS DEL CUARTEL DE INFANTERÍA PARA LA CIUDAD DE ZAMORA EN EL PRIMER TERCIO DEL SIGLO XVIII

Finalmente, en noviembre Moreau mandó a Madrid la propuesta modificada ${ }^{59}$, momento en que el proyecto de aprovechar el Pajar del Rey fue definitivamente descartado por dos razones contundentes que fueron enumeradas por el ingeniero director Diego Bordick ${ }^{60}$ en junio de 1737. La primera era la necesidad de dejar libre la muralla ante un eventual ataque, para maniobrar con mayor libertad y rapidez, ya que el estado de las fortificaciones era «excelente». Y por otro lado, el almacén de paja era necesario para abastecer al cuartel de caballería ${ }^{61}$. Por lo que el Pajar del Rey mantuvo su morfología, llevándose en él labores de mantenimiento en años posteriores $^{62}$.

\section{LA PROPUESTA DE UN CUARTEL DE INFANTERÍA JUNTO AL DE CABALLERÍA}

En enero de 1738, el ingeniero director Pedro Moreau remitió al duque de Montemar y a la Junta de Fortificaciones el plano de situación de una nueva propuesta para cuartel de infantería promovido desde el Consistorio zamorano, según mandato del gobernador Ginés de Hermosa. Éste le había transmitido que el cuartel existente podía alojar a mil infantes si se adecuaran las caballerizas, además de ubicar a su costado el cuartel de Infantería para un batallón, ocupando el mínimo espacio posible de las casas junto a la huerta del Cigarral (Fig. 1) ${ }^{63}$. A finales de ese mes, Juan Ballesteros y Juan de la Feriere, miembros de la Junta de Fortificaciones, le comunicaron al duque de Montemar que no veían inconveniente a este proyecto, ya que no tenían reparo alguno en el sitio que se proponía para construirlo. Sobre la

59. Ídem, carta de 13.11.1737. Verboom informó que debía conformarse una Junta de Arbitrios que gestionara el presupuesto para la construcción del cuartel que debería estar compuesta por el gobernador, dos diputados que éste señalara y el ingeniero segundo Bachelieu, estando la obra bajo la dirección de Moreau. Ídem, carta de 15.11.1737.

60. DIEGO BORDICK DEVEREZ (¿?-1756) fue un importante ingeniero militar. En 1700 ya realizó algunos planos de la plaza de Ceuta, pero no sería hasta 1718 cuando se le nombró ingeniero de segunda. Ascendió rápidamente tras estar bajo las órdenes de Verboom en la guerra de Sicilia, nombrado ingeniero director en 1731 como coronel de infantería. Trabajó en numerosos puntos, pero sobre todo en Sevilla y Extremadura, realizando algún plano sobre las plazas salmantinas de San Felices y el Fuerte de la Concepción, siendo ya brigadier. CAPEL, Horacio et alii: Los ingenieros militares en España, siglo XVIII: Repertorio biográfico e inventario de su labor cientifica y espacial. Barcelona, Universidad de Barcelona., 1983, p. 77.

61. AGS, SGU, leg. 3532. Carta de 15.06.1737.

62. En 1748 Pedro Pérez, por orden de la Junta de Arbitrios, dio condiciones (proyecto) para reparar el tejado del Pajar y adecuar parte de él para un cuerpo de guardia o cuartelillo. AHPZa, MZa, actas 1735, f. 163; AHPZa, prot. 2190, f. 171. Pedro Moreau había construido un cuerpo de guardia frente al puente pocos años antes.

63. AGS, SGU, leg. 3533, carta de 12.01.1738; AGS, SGU, leg. 3532, carta de 22.01.1738.

Ediciones Universidad de Salamanca / అ@@ Stud. his., H. ${ }^{a}$ mod., 41, n. 1 (2019), pp. 407-433 
adaptación de las cuadras del cuartel existente opinaban que «habrá que hacer algún gasto y no corto», no quedando clara su posición a favor o en contra ${ }^{64}$.

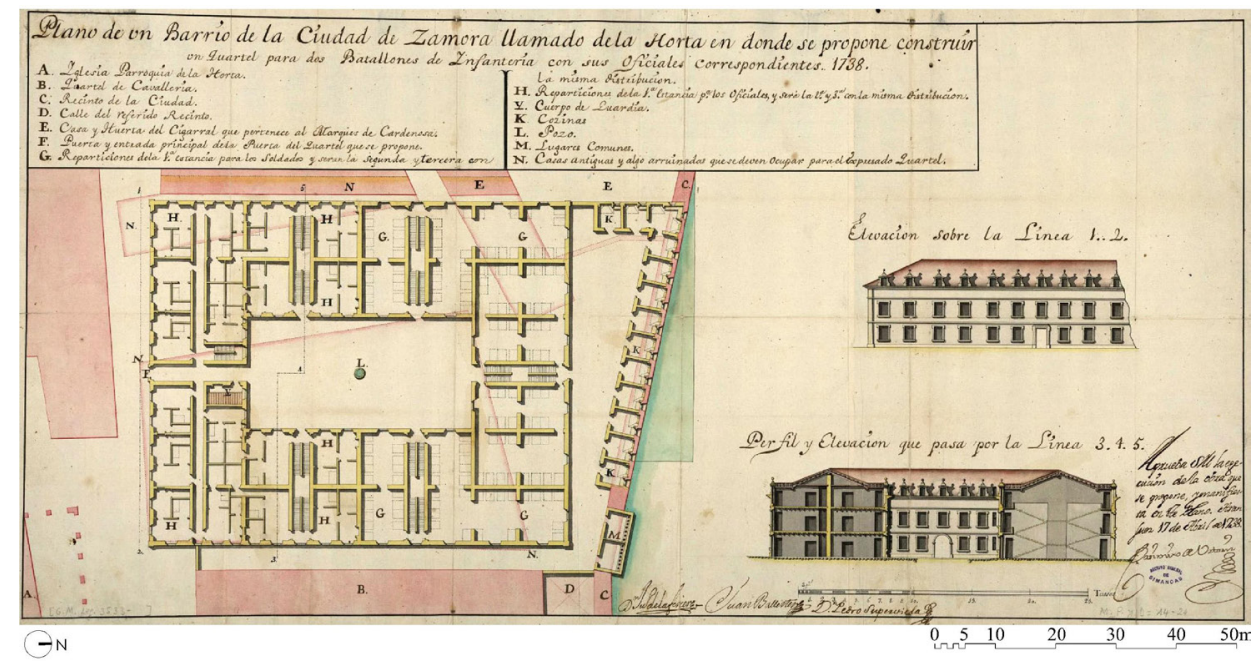

Fig. 12. Plano de la propuesta del cuartel de Infantería. 1738 (AGS, MPD, XIV-24).

El cuartel para dos batallones, soldados y oficiales seguía las mismas directrices que el vecino cuartel de Caballería en cuanto a su disposición centralizada en torno a un patio y en la utilización de dos plantas y bajocubierta, aunque elevando la línea del alero, por lo que desde el exterior destacaría por encima del cuartel vecino. En este caso, se llevó a cabo una distinción entre las dependencias para los oficiales, volcadas al callejón de acceso, y los dormitorios de la tropa, distribuidos en la mitad meridional del edificio, que a su vez se volcaba a un patio triangular cerrado con la muralla sobre la que se situaban las cocinas y letrinas. Pero sin lugar a dudas, lo más interesante del proyecto estaba en sus fachadas, mucho más refinadas que las austeras del cuartel de Caballería. Para este nuevo edificio se proponía un alzado de ventanas de grandes proporciones separadas horizontalmente por impostas. Se destacaban las esquinas y el zócalo. Los recercados de los huecos eran mucho más refinados que los de propuestas anteriores, así como las buhardillas, rematadas con una esfera sobre una pirámide que engalanaba más la fachada del edificio. Seguramente este esfuerzo decorativo solo se produciría en la fachada principal y el patio, ya que las laterales estaban volcadas a estrechos callejones.

64. AGS, SGU, leg. 3533, carta de 30.01.1738. 


\section{DANIEL LÓPEZ BRAGADO Y VÍCTOR-ANTONIO LAFUENTE SÁNCHEZ LOS PROYECTOS DEL CUARTEL DE INFANTERÍA PARA LA CIUDAD DE ZAMORA EN EL PRIMER TERCIO DEL SIGLO XVIII}

Ante lo afirmativo de la respuesta oficial, en febrero Pedro Moreau remitió el «tanteo» de esta nueva propuesta a Montemar ${ }^{65}$. Este documento incluía veinticuatro casas a expropiar con un coste total de 740.400 reales $^{66}$. Ésta acusada eliminación de la feligresía de la parroquia de Santa María de la Horta produjo la queja del prior del convento de San Juan de Jerusalén, fray Antonio de Cabra y Balboa, cenobio al que estaba vinculada. Éste propuso la construcción del cuartel en la zona de San Miguel, donde «todo son cortinas o campos labrados» (Fig. 1) ${ }^{67}$. Una vez más, ocurría que estando inmersos en la tramitación de un proyecto se intuía una nueva ubicación del mismo, contribuyendo a la continuación de la incertidumbre.

Finalmente, el 17 de abril de 1738, Sebastián de la Quadra, sustituto de José Patiño al frente de la secretaría de Estado, mandó una carta a Montemar informándole que Su Majestad aprobaba el proyecto ${ }^{68}$. Aunque las órdenes Reales ordenaban el inicio de las obras en el mes de abril, el proyecto no se llevó a cabo debido a las dudas locales de que las patologías del cuartel de «las Milicias», procedentes sobre todo de la humedad por la cercanía al río, se reprodujeran en el futuro cuartel de Infantería. Esta parálisis constructiva fue denunciada por Montemar a la Junta de Fortificaciones en julio ${ }^{69}$. La ubicación junto al cuartel de caballería y al Pajar del Rey generaría la identificación del barrio de la Horta con el núcleo del poder castrense en la ciudad. Sin embargo, si se hubiera llegado a construir habría obligado con el tiempo a disponer un gran espacio frente a él, a modo de plaza de armas, ya que la propuesta tenía frente a la puerta principal un callejón estrecho, difícilmente defendible e indigno para un cuartel militar, institución del Estado con mayor protagonismo en aquellos momentos.

Finalmente, el 20 de agosto, el nuevo corregidor de la ciudad, el mariscal de campo marqués de Gauna ${ }^{70}$, le envió una carta a Montemar explicándole que las

65. Dicho presupuesto lo había elaborado al maestro de obras José de Barcia por decisión conjunta de Leandro Bachelieu y del gobernador interino, que era el sargento mayor de Zamora

66. Cuando se reunieron Bachelieu y el gobernador interino era domingo, estando los vecinos ocupados por estar en la celebración de las Cuarenta Horas «estando todas las gentes de huelga» (festividad religiosa típica de los carnavales zamoranos) AGS, SGU, leg. 3533, carta de 22.02.1738.

67. AGS, SGU, leg. 3533, carta de 22.02.1738.

68. Le devolvieron el plano de Moreau firmado en Aranjuez por los componentes de la Junta de Fortificaciones Casimiro de Urztariz, Juan de la Feriere, Juan Ballester y Pedro Superviela como forma de expresar su beneplácito AGS, SGU, leg. 3533, carta de 17.04.1738; AGS, MPD, XIV-24.

69. AGS, SGU, leg. 3533, carta de 19.07.1738.

70. JUAN CARLOS HURTADO DE MENDOZA Y BROON (¿?-1738) marqués de Gauna, alcanzó el cargo militar de mariscal de campo y gobernador de Zamora desde agosto de 1738 hasta su fallecimiento a finales de ese mismo año. ALONSO DE CADENAS, Ampelio y DE CADENAS, Vicente: op. cit., p. 435.

Ediciones Universidad de Salamanca / 요 Stud. his., H. ${ }^{a}$ mod., 41, n. 1 (2019), pp. 407-433 


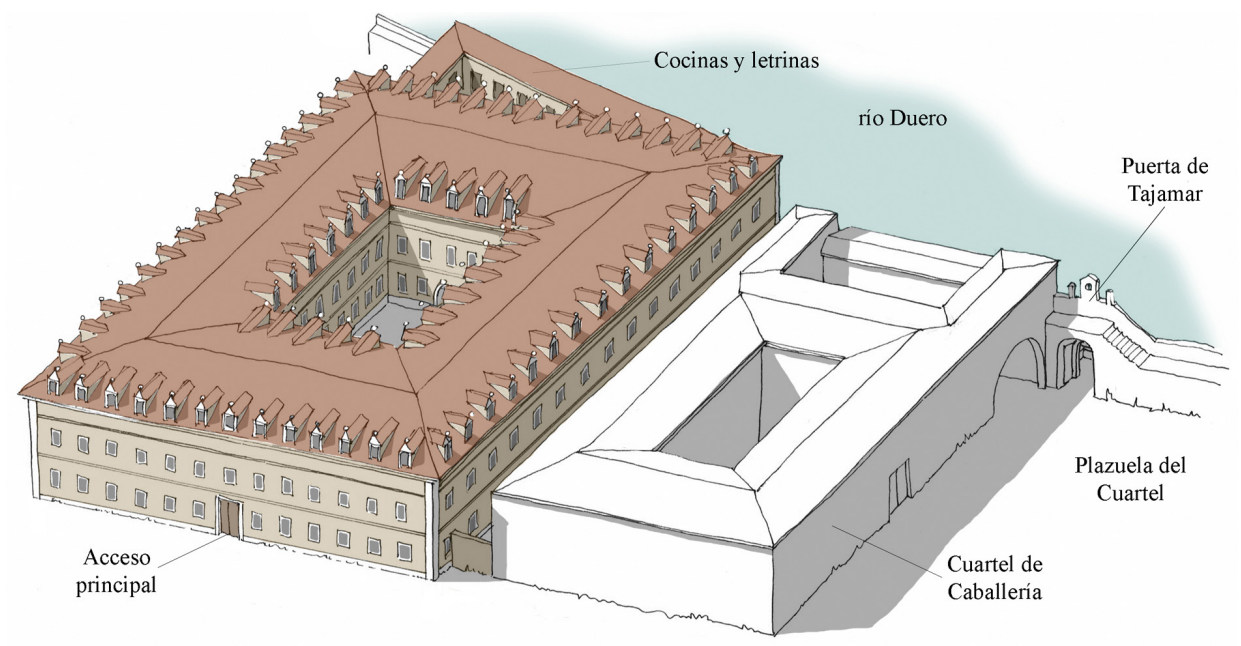

Fig. 13. Restitución de la propuesta del cuartel de 1738 (elaboración propia basándose en AGS, $M P D, X I V-24)$.

expropiaciones para construir el nuevo cuartel de Infantería tendrían un alto costo, problemas de cimentación por la cercanía del agua, además de la pérdida de feligresía en la parroquia de la Horta, dada la imposibilidad para realojarlos dentro del barrio ante el reducido número de viviendas que existía. Sin embargo, ninguno de estos problemas concurría en las huertas de San Miguel, donde todo eran ventajas: sitio más sano, los cimientos más seguros, menor coste, en una zona despoblada y distante del río. De este modo se desvanecía el proyecto de Pedro Moreau de construir el cuartel junto al de Caballería. Al igual que las otras propuestas, los propios responsables de la ciudad daban al traste con el tercer intento de construir un cuartel de Infantería del todo necesario para desahogar a los vecinos de la ciudad que daban alojamiento al excedente de soldados.

\section{CONCLUSIONES}

El objetivo final de esta investigación es esclarecer el proceso de elaboración y el contenido de los tres primeros proyectos del infructuoso cuartel de Infantería de Zamora. Como se ha comprobado fue un largo camino lleno de problemas económicos, personales y políticos. Las propuestas en el barrio de la Horta no llegaron a buen fin, no porque no fuera necesaria su construcción, que lo era desde el primer momento, sino por malos planteamientos que heredaban los gobernantes de sus antecesores, así como de unos técnicos sobrepasados por el trabajo y la carestía de 


\section{DANIEL LÓPEZ BRAGADO Y VÍCTOR-ANTONIO LAFUENTE SÁNCHEZ LOS PROYECTOS DEL CUARTEL DE INFANTERÍA PARA LA CIUDAD DE ZAMORA EN EL PRIMER TERCIO DEL SIGLO XVIII}

medios. Decisiones técnicas y políticas, enemistades personales entre sus protagonistas, la falta de medios económicos y, sobre todo, la incapacidad para la elección de un solar aceptable, frustrarían la construcción del ansiado y esperado cuartel de Zamora. De entre todas estas cosas, quizás la más relevante fue la mala elección del terreno, ya fuera por su reducido tamaño, por los problemas de humedad del suelo, por el peligro de inundarse o por el gran número de viviendas que hacía falta expropiar y el derribar.

Fueron varios los protagonistas de estos proyectos, tanto los ingenieros redactores como los gobernantes, todos involucrados en una lenta burocracia, exponente máximo del centralismo borbónico que, por suerte, generó un vasto epistolario que testifica las causas de la impotencia constructora de este edificio. Finalmente, su construcción tendría lugar en un punto distante de este barrio, y medio siglo después de que en 1715 se iniciase este proceso. La materialización final de este ansiado cuartel bien merece la dedicación de un capítulo aparte ${ }^{71}$.

\section{REFERENCIAS BIBLIOGRÁFICAS}

ALMARAZ VÁZQUEZ, Ma de las Mercedes y BLANCO SÁNCHEZ, José Ángel: «Consideraciones sobre el arquitecto José de Barcia». En Studia Zamorensia. Zamora: Colegio Universitario de Zamora, Centro Asociado de la UNED, Segunda Etapa, vol. VIII, 2008, pp. 149-179.

ALMARAZ VÁZQUEZ, Ma de las Mercedes y BLANCO SÁNCHEZ, José Ángel: «La construcción de las panaderías de Zamora y la intervención del arquitecto Manuel Martín Rodríguez». En Anuario IEZFO. Zamora: Instituto de Estudios Zamoranos Florián de Ocampo, Diputación de Zamora, 2010, pp. 191-218.

ALONSO DE CADENAS, Ampelio y DE CADENAS, Vicente: Elenco de grandezas y títulos nobiliarios españoles. Madrid: Hidalguía, 2002.

ALONSO RODRÍGUEZ, Marta: «El ensanche de la plaza de la Catedral de Oviedo. Estudio y restitución gráfica», en Revista EGA. Valencia: Editorial de la Universitat Politècnica de València, 2014, pp. 242-251.

CAPEL, Horacio et alii: Los ingenieros militares en España, siglo XVIII: repertorio biográfico e inventario de su labor cientifica y espacial. Barcelona: Universidad de Barcelona, 1983.

CAPEL, Horacio et alii: De Palas a Minerva: la formación cientifica y la estructura institucional de los ingenieros militares en el siglo XVIII. Barcelona: Serbal, 1988.

CARAZO LEFORT, Eduardo: Valladolid: forma urbis: restitución infográfica del patrimonio urbano perdido. Valladolid: Ayuntamiento de Valladolid, 2009.

CARRACEDO PRIMO, José E.: Historia militar de Zamora desde el siglo XVIII. Zamora, Instituto de Estudios Zamoranos Florián de Ocampo, Diputación de Zamora, 2014.

71. LÓPEZ BRAGADO, Daniel; LAFUENTE SÁNCHEZ, Víctor-Antonio: op. cit.

Ediciones Universidad de Salamanca / 요 Stud. his., H. ${ }^{a}$ mod., 41, n. 1 (2019), pp. 407-433 
DANIEL LÓPEZ BRAGADO Y VÍCTOR-ANTONIO LAFUENTE SÁNCHEZ LOS PROYECTOS DEL CUARTEL DE INFANTERÍA PARA LA CIUDAD DE ZAMORA EN EL PRIMER TERCIO DEL SIGLO XVIII

FERNÁNDEZ DURO, Cesáreo: Memorias Históricas de Zamora, su provincia y obispado. Madrid: Sucesores de Ribadeneyra, t. III, 1888.

LARRÉN IZQUIERDO, Hortensia et alii: Fortificaciones abaluartadas de la provincia de Zamora. Valladolid: Junta de Castilla y León, 2010.

LÓPEZ BRAGADO, Daniel; LAFUENTE SÁNCHEZ, Víctor-Antonio: «La construcción de edificios militares en el tercio central del siglo XVIII en la ciudad de Zamora». En Anuario 2017. Zamora: Diputación de Zamora, Instituto de Estudios Zamoranos Florián de Ocampo, 2018, pp. 279-318.

DE LUIS CALABUIG, Ángel de: Ciudad Rodrigo: las fortificaciones. Ciudad Rodrigo, ADECOIR, Ayuntamiento de Ciudad Rodrigo, 2009.

MANZANO MONIS, Manuel: «El Mariscal de Campo D. Pedro Moreau y el Fuerte de la Concepción». En Academia. Madrid: Real Academia de Bellas Artes de San Fernando, no 52, 1981, pp. 201-249.

MUÑOZ CORBALÁN, Juan Miguel: Jorge Próspero Verboom. Ingeniero militar flamenco de la monarquía hispánica. Madrid: Fundación Juanelo Turriano de Historia de la Ingeniería, 2015.

MUÑOZ MIÑAMBRES, José: Porque Zamora es así: siglo XVIII. Zamora: Imprenta Jambrina, 2000.

MARTÍN BAILÓN, Marco Antonio y PÉREZ MARTÍN, Sergio (coord.): «Comentarios a la lámina 42» en Zamora año de 1850: cuaderno de vistas de Zamora tomadas del natural y ejecutadas por Don José $M^{a}$ Avrial y Flores. Zamora: Real Academia de Bellas Artes de San Fernando, Ayuntamiento de Zamora, Diputación de Zamora, Instituto de Estudios Zamoranos Florián de Ocampo, Imprenta Jambrina, 2013, pp.252-254.

SÁNCHEZ RIVERA, María Luisa: Fuentes documentales zamoranas en el Archivo de Simancas. Zamora: Diputación de Zamora, Instituto de Estudios Zamoranos Florián de Ocampo, 1990.

TOVAR MARTÍN, Virginia: «Esteban Marchand y Leandro Bachelieu, ingenieros franceses en las obras del Real Sitio de Aranjuez». En Anales de historia del arte. Madrid: Universidad Complutense de Madrid. nº, 1998, pp. 291-308.

RUPÉREZ ALMAJANO, $\mathrm{M}^{\mathrm{a}}$ Nieves: «Aspectos del urbanismo zamorano en el siglo XVIII. La junta de policía». En Actas del primer congreso de Historia de Zamora. Zamora: Diputación de Zamora, Instituto de Estudios Zamoranos Florián de Ocampo, tomo 4, 1991, pp. 175-194.

VEGA VIERA, Víctor-Javier: «Planos y dibujos de la ciudad de Zamora en el Archivo General de Simancas». En Actas de Fuentes y métodos de la historia local. Zamora: Instituto de Estudios Zamoranos Florián de Ocampo, 1991, pp. 205-232. 
